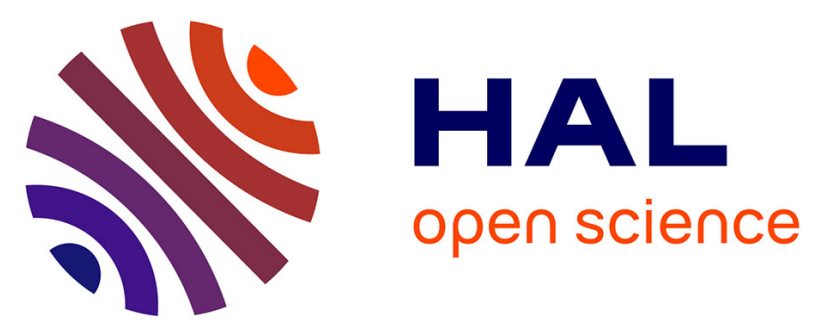

\title{
Self-Assembly of Telechelic Tyrosine End-Capped PEO and Poly(alanine) Polymers in Aqueous Solution
}

\author{
Steven Kirkham, Valeria Castelletto, Ian William Hamley, Mehedi Reza,
} Janne Ruokolainen, Daniel Hermida-Merino, Panayiotis Bilalis, Hermis Iatrou

\section{- To cite this version:}

Steven Kirkham, Valeria Castelletto, Ian William Hamley, Mehedi Reza, Janne Ruokolainen, et al.. Self-Assembly of Telechelic Tyrosine End-Capped PEO and Poly(alanine) Polymers in Aqueous Solution. Biomacromolecules, 2016, 17 (3), pp.1186-1197. 10.1021/acs.biomac.6b00023 . hal-01572885

\section{HAL Id: hal-01572885 \\ https://hal.science/hal-01572885}

Submitted on 8 Aug 2017

HAL is a multi-disciplinary open access archive for the deposit and dissemination of scientific research documents, whether they are published or not. The documents may come from teaching and research institutions in France or abroad, or from public or private research centers.
L'archive ouverte pluridisciplinaire $\mathbf{H A L}$, est destinée au dépôt et à la diffusion de documents scientifiques de niveau recherche, publiés ou non, émanant des établissements d'enseignement et de recherche français ou étrangers, des laboratoires publics ou privés. 


\title{
Self-Assembly of Telechelic Tyrosine End-Capped PEO and Poly(alanine) Polymers in Aqueous Solution
}

\author{
Steven Kirkham, ${ }^{\dagger}$ Valeria Castelletto, ${ }^{\dagger}$ Ian William Hamley, ${ }^{*}{ }^{\dagger}$ Mehedi Reza, ${ }^{\ddagger}$ Janne Ruokolainen, ${ }^{\dagger}$ \\ Daniel Hermida-Merino, ${ }^{\S}$ Panayiotis Bilalis," and Hermis Iatrou" \\ ${ }^{\dagger}$ School of Chemistry, Pharmacy and Food Biosciences, University of Reading, Whiteknights, Reading RG6 6AD, United Kingdom \\ ${ }^{\ddagger}$ Department of Applied Physics, Aalto University School of Science, P.O. Box 15100 FI-00076 Aalto, Finland \\ ${ }^{\S}$ ESRF-The European Synchrotron, Grenoble 38000, France \\ "University of Athens, Department of Chemistry, Panepistimiopolis Zografou, 15771 Athens, Greece
}

\section{Supporting Information}

ABSTRACT: The self-assembly in aqueous solution of three novel telechelic conjugates comprising a central hydrophilic polymer and short (trimeric or pentameric) tyrosine end-caps has been investigated. Two of the conjugates have a central poly(oxyethylene) (polyethylene oxide, PEO) central block with different molar masses. The other conjugate has a central poly(L-alanine) (PAla) sequence in a purely amino-acid based conjugate. All three conjugates self-assemble into $\beta$ sheet based fibrillar structures, although the fibrillar morphology revealed by cryogenic-TEM is distinct for the three polymers-in particular the Tyr5-PEO6k-Tyr5 forms a population of short straight fibrils in contrast to the more diffuse fibril aggregates observed for Tyr5PEO2k-Tyr5 and Tyr3-PAla-Tyr3. Hydrogel formation was not observed for these samples (in contrast to prior work on related systems) up to quite high concentrations, showing that it is possible to prepare solutions of peptide-polymer-peptide conjugates with hydrophobic end-caps without conformational constraints associated with hydrogelation. The Tyr5-PEO6k-Tyr5 shows significant PEO crystallization upon drying in contrast to the Tyr5PEO2k-Tyr5 conjugate. Our findings point to the remarkable ability of short hydrophobic peptide end groups to modulate the self-assembly properties of polymers in solution in model peptide-capped "associative polymers". Retention of fluidity at high conjugate concentration may be valuable in potential future applications of these conjugates as bioresponsive or biocompatible materials, for example exploiting the enzyme-responsiveness of the tyrosine end-groups.

\section{INTRODUCTION}

Conjugation of polymers with peptides enables the unique properties of each component to be combined, leading to novel biomacromolecules with a diversity of potential applications. ${ }^{1-8}$ In particular, polymers can be synthesized inexpensively and attached to peptides, modifying their solubility and aggregation properties. On the other hand, modification of polymers with peptides provides biofunctionality of many types, depending on the peptide and on the mode of incorporation, i.e., whether laterally attached where the peptide motif forms part of the polymer repeating unit, or whether attached at one or both ends of the polymer. Novel materials can result from the combination of polymer and peptide including lyotropic liquid crystal phases in aqueous solution ${ }^{9-11}$ or hydrogels. ${ }^{12-17}$

Hydrophilic polymers may be modified with hydrophobic end groups to create telechelic polymers, which among other properties resulting from the noncovalent association of the end groups, possess useful rheological behavior. This is exploited in associative polymers ${ }^{18-20}$ widely used as thickeners in a variety of applications, and in commercially available polyethylene glycol (PEG)-based polymers such as reverse Pluronics, ${ }^{20}$ for example. In the field of peptide biomaterials, it has been proposed that polymers such as PEG or PEO (poly(ethylene oxide)) may be used as inert spacers within peptide sequences to improve stability and circulation time of the biomolecules for applications such as gene delivery, ${ }^{21}$ or cell signaling. ${ }^{22}$ In the field of purely peptide/protein systems (i.e., systems not incorporating synthetic polymers), the properties of gels of genetically expressed proteins comprising a hydrophilic random coil-like middle block and collagen-like end blocks have been investigated by the groups of Tirrell ${ }^{12,23}$ and Cohen-Stuart. ${ }^{24-26}$

There are still few papers investigating the properties of selfassembled telechelic peptide-polymer-peptide conjugates. In a recent paper, the Hamley group reported on the gel-sol transition of conjugates of PEO with hydrophobic dipeptides,

Received: January 7, 2016

Revised: February 9, 2016

Published: February 11, 2016 
Scheme 1. Synthesis Route for Tyr-PEO-Tyr Samples

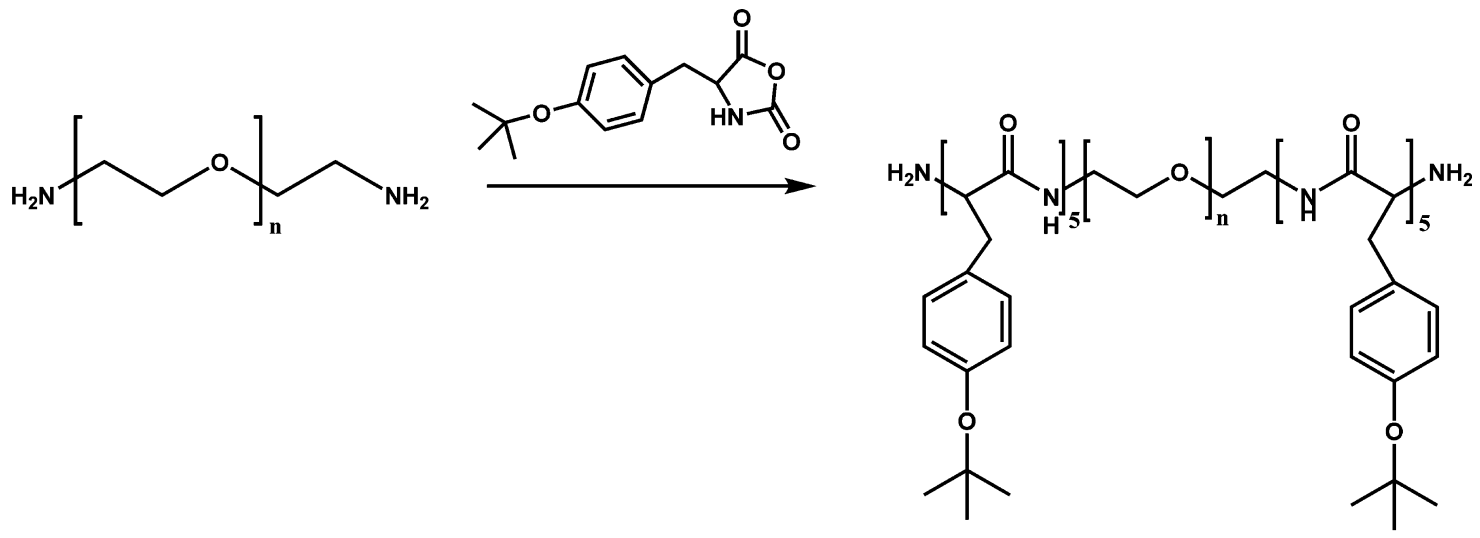

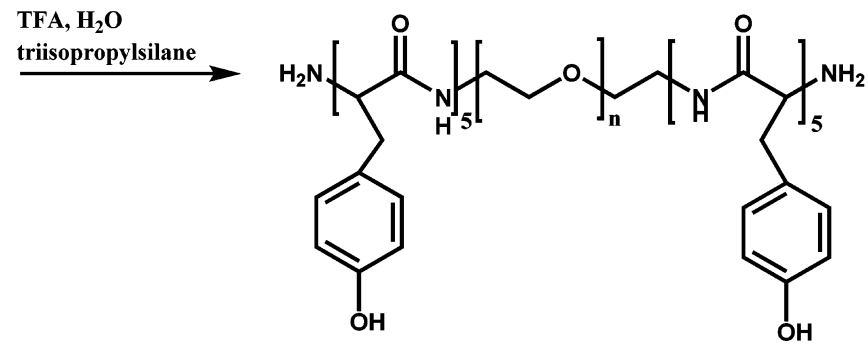

including dityrosine and diphenylalanine. ${ }^{17}$ The conjugates were synthesized by coupling the dipeptides to bis-aminopropyl PEO of molar mass $1500 \mathrm{~g} \mathrm{~mol}^{-1}$. The Fmoc ( $N$-fluorenyl-9methoxycarbonyl) protecting group (used in the peptide synthesis) was retained in some of the conjugates prepared, at one or both termini. This influences the hydrophilelipophile balance and hence has a significant effect on the selfassembly behavior. Remarkably, one conjugate comprising dityrosine end-caps and with $\mathrm{C}$-terminal Fmoc was found to undergo a gel-sol transition near body temperature, and this was shown to be driven by the loss of $\beta$-sheet secondary structure, associated with the formation of extended fibrils. The Lendlein group later prepared similar telechelic conjugates of desaminotyrosine (DAT) or desaminotyrosyl-tyrosine (DATT) with a linear PEG3000 midblock and also a form arm-PEG conjugate. ${ }^{27} \mathrm{~A}$ critical aggregation concentration was noted for the linear midblock conjugate, pointing toward self-assembly at high concentration. ${ }^{27}$ The rheological properties of hydrogels formed by linear and star-shaped oligo-ethylene glycol/DATT conjugates were examined. The same group also investigated the structural, conformational and rheological properties of gelatin (which has a collagen-based helical structure) functionalized with DAT or DATT at lysine residues. ${ }^{28,29}$ Micelles have been reported for PLL-PEG-PLL copolymers, where PLL denotes poly(L-leucine), the PLL adopting an $\alpha$-helical conformation. ${ }^{30}$ Release of encapsulated drug was also investigated and sustained release over times 100-200 h was observed. Fibrillar hydrogels have recently been reported for a PAla-PGlu-PAla [PGlu: poly(L-glutamic acid)] conjugate selfassembling in aqueous buffer solution. ${ }^{31}$

In the present paper, we investigate the self-assembly in aqueous solution of conjugates comprising telechelic polymers capped with short (pentameric or trimeric) tyrosine sequences. The creation of tyrosine-functionalized polymers is of interest in the development of novel aqueous biomaterials and hydrogel systems. In contrast to our previous study, ${ }^{17}$ the polymers are prepared by living NCA polymerization techniques, which give greater flexibility to tailor block length and which enable here the creation of novel purely peptidic conjugates with a central poly(L-alanine) block. The central core polymer in these designed telechelic conjugates is either PEO with molar mass of $2 \mathrm{~kg} \mathrm{~mol}^{-1}$ or $6 \mathrm{~kg} \mathrm{~mol}^{-1}$ or poly(L-alanine). According to most hydrophobicity scales, tyrosine is considered hydrophobic, ${ }^{32,33}$ (although not according to the Kyte-Doolittle scale ${ }^{34}$ ) and capable of undergoing aromatic stacking interactions. Tyrosine has interesting functionality, as it is involved in cell signaling and is responsive to enzymes including kinases and phosphatases, which add and delete phosphate groups, respectively. It also has interesting fluorescence properties. Alanine is somewhat hydrophilic, at least according to the White-Wimley hydrophobicity scale, ${ }^{32,33}$ and so the $\mathrm{Tyr}_{3}$ -

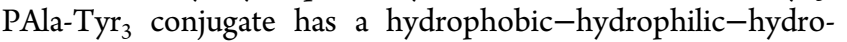
phobic architecture analogous to that of the two PEO conjugates, although with a purely amino acid based architecture (which may be of relevance to future applications where bioactivity is important). We find using a comprehensive suite of characterization measurements that all three novel conjugates form $\beta$-sheet-based fibrillar structures via selfassembly in aqueous solution, although the fibril morphology is distinct for the three conjugates. Unexpectedly, hydrogel formation was not observed up to rather high polymer concentration, enabling the production of high polymer/ peptide conjugate content liquids. The influence of PEO crystallization on drying films is examined for the $\mathrm{Tyr}_{5}$-PEO2k$\mathrm{Tyr}_{5}$ and $\mathrm{Tyr}_{5}-\mathrm{PEO} 6 \mathrm{k}-\mathrm{Tyr}_{5}$ conjugates, representing the first study to our knowledge on crystallization in this class of polymer/peptide conjugate that provides insight into PEO crystallization when constrained within a telechelic architecture.

\section{EXPERIMENTAL SECTION}

Materials. $\mathrm{N}$-(tert-Butoxycarbonyl)-L-tyrosine, Boc-Tyr $(\mathrm{tBu})-\mathrm{OH}$, (99\%) was purchased from Bachem. Poly(ethylene oxide) bis(amine) with molecular weights of $5.9 \times 10^{3} \mathrm{~g} / \mathrm{mol}$ and $2.0 \times 10^{3} \mathrm{~g} / \mathrm{mol}$ were purchased from Aldrich and were used as difunctional macroinitiators. 


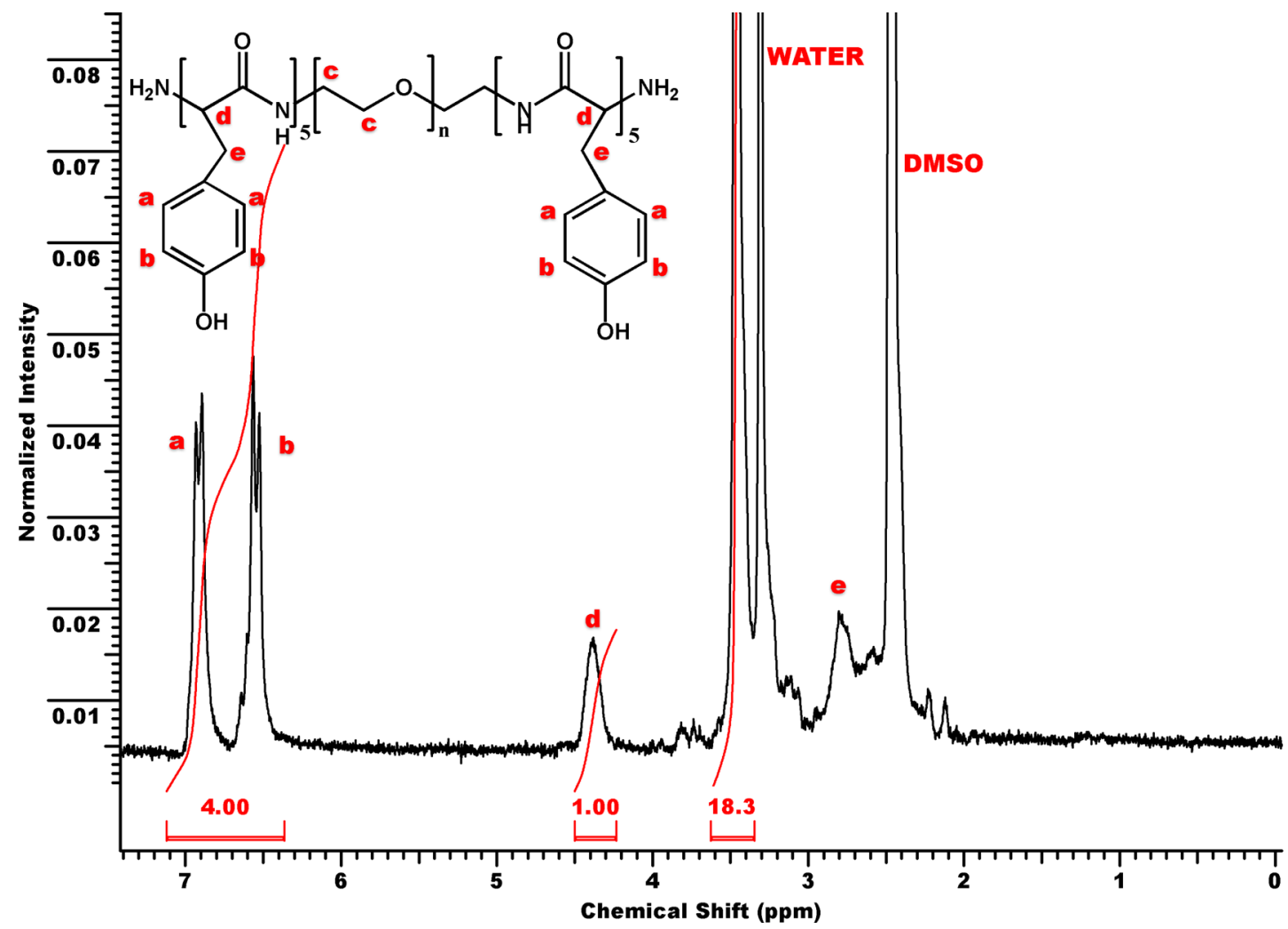

Figure 1. ${ }^{1} \mathrm{H}$ NMR spectrum of the $\mathrm{Tyr}_{5}-\mathrm{PEO} 2 \mathrm{k}-\mathrm{PTyr}_{5}$ triblock copolymer. Two sharp solvent peaks are assigned to DMSO at 2.54 ppm and one from water in DMSO at $3.33 \mathrm{ppm}^{71}$

Ethylenediamine $(\geq 99 \%)$ was obtained from Aldrich and was left to dry over a sodium mirror for $24 \mathrm{~h}$. It was then distilled into precalibrated ampules, diluted with purified DMF to the appropriate concentration, subdivided into ampules, and stored under high vacuum at $-20{ }^{\circ} \mathrm{C}$. Thionyl chloride (99.7\%, Acros Organics) was distilled prior to use. The solvent purification was performed using standard high vacuum techniques reported elsewhere. ${ }^{35}$

Synthesis of the novel tert-Butyl protected N-carboxy anhydride of L-Tyrosine (Tyr(tBu)-NCA). See Supporting Information (SI) Scheme S1. Boc-Tyr (tBu)-OH (3 g, $8.9 \mathrm{mmol})$ was added to a round-bottom flask with a stir bar and dried overnight under high vacuum. Then $30 \mathrm{~mL}$ of THF was distilled in the flask, giving a clear solution. The reaction flask was placed in an ice-bath, filled with argon, and $0.95 \mathrm{~mL}$ ( $13.1 \mathrm{mmol})$ of thionyl chloride diluted in $10 \mathrm{~mL}$ of THF was added dropwise in a period of $10 \mathrm{~min}$. The reaction was left at 0 ${ }^{\circ} \mathrm{C}$ for $1 \mathrm{~h}$ and at $25^{\circ} \mathrm{C}$ for $3 \mathrm{~h}$, giving a clear yellow solution. Then the solution was poured into $700 \mathrm{~mL}$ of hexane, and a yellow solid was precipitated. The solid was filtered and then transferred to a roundbottom flask. A quantity $40 \mathrm{~mL}$ of ethyl acetate was distilled giving a yellow suspension. The suspension was filtered, and the filtrate was poured into $600 \mathrm{~mL}$ of hexane under vigorous stirring. Finally, the white solid precipitate $\operatorname{Tyr}(\mathrm{tBu})-\mathrm{NCA}$ was isolated by filtration and dried overnight, under high vacuum, to afford $1.85 \mathrm{~g}$ (7.0 mmol, 79\% yield). The purity of Tyr(tBu)-NCA was confirmed by ${ }^{1} \mathrm{H}$ NMR and FTIR spectroscopy, shown in Supporting Information Figures S1 and S2, respectively.

Synthesis of N-Carboxy Anhydride of L-Alanine (Ala-NCA). The synthesis process of the L-alanine NCA (Ala-NCA) was accomplished according to a previously published method. ${ }^{35}$

Synthesis of Poly(L-tyrosine)-PEO-Poly(L-tyrosine). (a). Synthesis of $\mathrm{Tyr}_{5}-\mathrm{PEO} \mathrm{k}-\mathrm{Tyr}_{5}$. PEO bis(amine) $(0.57 \mathrm{~g} ; 0.28 \mathrm{mmol})$ with $M_{\mathrm{n}}=2.0 \times 10^{3} \mathrm{~g} / \mathrm{mol}$ was added to a round-bottom flask. Twenty milliliters of highly dry benzene was distilled, and the macroinitiator was dissolved. The solution was stirred for $2 \mathrm{~h}$, and benzene was distilled off to dryness. This procedure removes residual water in the $\mathrm{PEO}$, which can initiate NCA polymerization. Subsequently, $20 \mathrm{~mL}$ of highly pure DMF was distilled followed by dissolution of the macroinitiator. Then $0.70 \mathrm{~g}(2.66 \mathrm{mmol})$ of $\mathrm{Tyr}(\mathrm{tBu})-\mathrm{NCA}$, dissolved in $5 \mathrm{~mL}$ of DMF, was added. Periodically, the solution was pumped to remove the $\mathrm{CO}_{2}$ produced from polymerization. After completion of the polymerization (observed when bubbling of THF solution stopped), the polymer was precipitated in diethyl ether and dried under high vacuum. For the deprotection of $\mathrm{tBu}$ groups, ${ }^{36}$ the copolymer was suspended in $\mathrm{CH}_{2} \mathrm{Cl}_{2}(20 \% \mathrm{w} / \mathrm{v})$ and an equal volume of trifluoroacetic acid (TFA) was added along with $0.5 \mathrm{~mL}$ of $\mathrm{H}_{2} \mathrm{O}$. The polymer was completely dissolved and was left to be deprotected for $1 \mathrm{~h}$ at room temperature. Subsequently, an equimolar amount (with respect to the number of Tyr monomeric units) of triisopropyl silane was added. The solution was poured into diethyl ether, and the white solid was filtered, dried, diluted in water and dialyzed against $2 \mathrm{~L}$ of Milli-Q water for four times. Finally, the polymer solution was freeze-dried to yield $\mathrm{Tyr}_{5}-\mathrm{PEO} 2 \mathrm{k}-\mathrm{Tyr}_{5}$ as a white powder. The reactions used are given in Scheme 1.

(b). Synthesis of $T y r_{5}-P E O 6 k-T y r_{5}$. The synthetic method followed for the $\mathrm{Tyr}_{5}-\mathrm{PEO} 6 \mathrm{k}-\mathrm{Tyr}_{5}$ was similar to that described above. Briefly, $0.95 \mathrm{~g}(0.16 \mathrm{mmol})$ of PEO bis(amine) with $M_{\mathrm{n}}=5.9 \times 10^{3} \mathrm{~g} / \mathrm{mol}$ and $0.40 \mathrm{~g}(1.52 \mathrm{mmol})$ of $\mathrm{Tyr}(\mathrm{tBu})-\mathrm{NCA}$ were used. The reaction takes $3-4 \mathrm{~h}$.

The PEO precursors as well as the final copolymers containing PEO with $M_{\mathrm{n}}=2.0 \times 10^{3} \mathrm{~g} / \mathrm{mol}$ or $5.9 \times 10^{3} \mathrm{~g} / \mathrm{mol}$ were characterized by ${ }^{1} \mathrm{H}$ NMR spectroscopy (Figure 1) and size exclusion chromatography featuring a two-angle laser light scattering detector (Figure 2). From the FTIR spectrum (Supporting Information Figure S2), it is obvious that the peak of the Boc- protection of the amine groups at $1736 \mathrm{~cm}^{-1}$ is completely eliminated after the formation of the NCA, while the peaks at 1848 and $1741 \mathrm{~cm}^{-1}$ have developed, corresponding to the carbonyl groups of the cyclic N-carboxy anhydride.

Synthesis of Poly(L-tyrosine)-Poly(L-alanine)-Poly(L-tyrosine). Polymerization was carried out with ethylenediamine as the initiator. The sequential addition methodology was used for the synthesis of the triblock polypeptide. Ala-NCA (0.36 g) was diluted in $10 \mathrm{~mL}$ of DMF, and $2 \mathrm{~mL}$ of ethylenediamine solution in DMF (1.89 


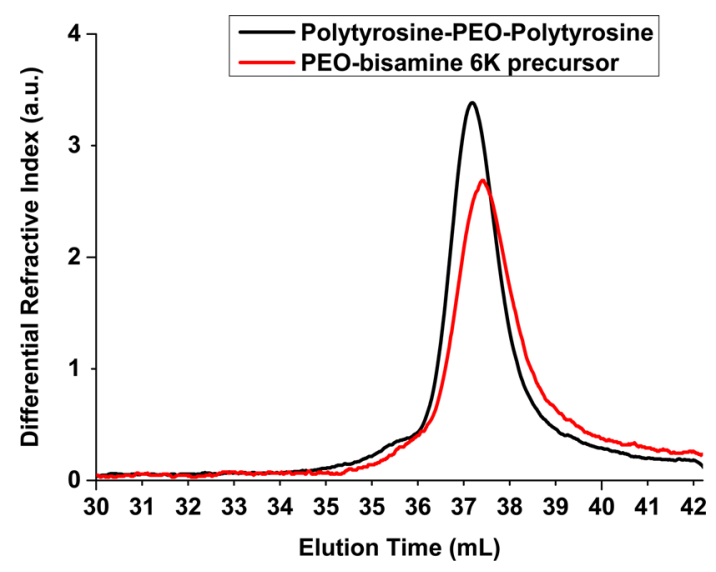

Figure 2. SEC chromatogram of the $\mathrm{Tyr}_{5}-\mathrm{PEO} 6 \mathrm{k}-\mathrm{Tyr}_{5}$ triblock copolymer.

$\times 10^{-5} \mathrm{~mol} / \mathrm{mL}$ ) was added. An aliquot of the solution was removed after the completion of the polymerization ( 2 days) for characterization of the poly(L-alanine) block. Then, $0.05 \mathrm{~g}$ of $\mathrm{Tyr}(\mathrm{tBu})-\mathrm{NCA}$ was then added and was left to react until all monomer was completely consumed. After complete consumption of $\mathrm{Tyr}(\mathrm{tBu})$-NCA ( 2 days), the final triblock copolymer was precipitated in diethyl ether, filtered, and dried to constant weight. For the deprotection of $\mathrm{tBu}$ groups, the same procedure as above was followed. Finally, poly(L-tyrosine)poly(L-alanine $)$-poly(L-tyrosine $)$ was produced as a white powder. The reactions used are given in Scheme 2. The final copolypeptide was characterized only by ${ }^{1} \mathrm{H}$ NMR spectroscopy (Figure 3 ), since it was not soluble in DMF.

Methods. Size Exclusion Chromatography. Size-exclusion chromatography (SEC) was used to determine the $M_{\mathrm{n}}$ and $M_{\mathrm{w}} / M_{\mathrm{n}}$ values. The analysis was performed using a system that was composed of a Waters 600 high pressure liquid chromatographic pump, Waters Ultrastyragel columns (HR-2, HR-4, HR-5E, and HR-6E), a Waters 410 differential refractometer detector and a Precision PD 2020 two angle $\left(15^{\circ}, 90^{\circ}\right)$ light scattering detector at $60^{\circ} \mathrm{C}$. A $0.1 \mathrm{~N} \mathrm{LiBr} \mathrm{DMF}$ solution was used as an eluent at a rate of $1 \mathrm{~mL} / \mathrm{min}$ (SEC-TALLS).

NMR and FTIR Spectroscopy. ${ }^{1} \mathrm{H}$ NMR spectroscopy $(300 \mathrm{MHz})$ was performed using a Varian Unity Plus 300/54 spectrometer. The spectra of the polymers were measured either in deuterated DMSO (NCA and poly(L-tyrosine)-PEO-poly(L-tyrosine)) or in $\mathrm{CF}_{3} \mathrm{COOD}$ (the $\mathrm{Tyr}_{3}-\mathrm{PAla}-\mathrm{Tyr}_{3}$ copolypeptide). FTIR measurements were performed with a PerkinElmer Spectrum One instrument, in $\mathrm{KBr}$ pellets at room temperature, spectra being recorded over the range $450-4000 \mathrm{~cm}^{-1}$.

Sample Preparation. The solubility of samples dissolved into water was found to be poor but $\mathrm{pH}$ adjustment to 12 (above the $\mathrm{p} K_{\mathrm{a}}$ of tyrosine $\mathrm{e}^{37}$ ) using an $\mathrm{NaOH}$ solution led to satisfactory solubility, therefore this was the $\mathrm{pH}$ value selected for all measurements for samples $\mathrm{Tyr}_{5}-\mathrm{PEO} 2 \mathrm{k}-\mathrm{Tyr}_{5}$ and Tyr3-PAla-Tyr3. Since sample $\mathrm{Tyr}_{5}-$ PEO6k-Tyr 5 was found to show good solubility in water, it was also studied at its native $\mathrm{pH}, \mathrm{pH} 5.69$.

Circular Dichroism. CD spectra were recorded using a Chirascan spectropolarimeter (Applied Photophysics, UK) in the wavelength range $190-320 \mathrm{~nm}$. The samples, $0.5 \%$ in water raised to $\mathrm{pH} 12$ or native $\mathrm{pH}$ for $\mathrm{Tyr}_{5}-\mathrm{PEO} 6 \mathrm{~K}-\mathrm{Tyr}_{5}$, were placed in a coverslip cuvette $(0.1 \mathrm{~mm}$ thick), with spectra presented with absorbance $\mathrm{A}<2$ at any measured point with a $0.5 \mathrm{~nm}$ step, $1 \mathrm{~nm}$ bandwidth, and $1 \mathrm{~s}$ collection time per step. Samples were acclimatized at each increasing $10{ }^{\circ} \mathrm{C}$ temperature point for $5 \mathrm{~min}$, and $30 \mathrm{~min}$ for the $60-20{ }^{\circ} \mathrm{C}$ change, before measurements were taken. The $\mathrm{CD}$ signal from the background was subtracted from the $\mathrm{CD}$ spectra of the sample solutions.

FTIR. For the secondary structure studies, spectra were recorded using a Thermo Scientific Nicolet IS5 and a Nexus-FTIR spectrometer, both equipped with a DTGS detector. A $40 \mu \mathrm{L}$ drop of the sample (in $\mathrm{D}_{2} \mathrm{O}$ ) was sandwiched between two $\mathrm{CaF}_{2}$ plate windows, with a $0.006 \mathrm{~mm}$ thick Mylar spacer) in a Specac GS20500 sample cell holder. Cells were heated using a Specac 4000 series high

Scheme 2. Reactions Used for the Synthesis of the Poly(L-tyrosine)-Poly(L-alanine)-Poly(L-tyrosine) Triblock Copolymer ( $m$ $=6$ and $n=64)$

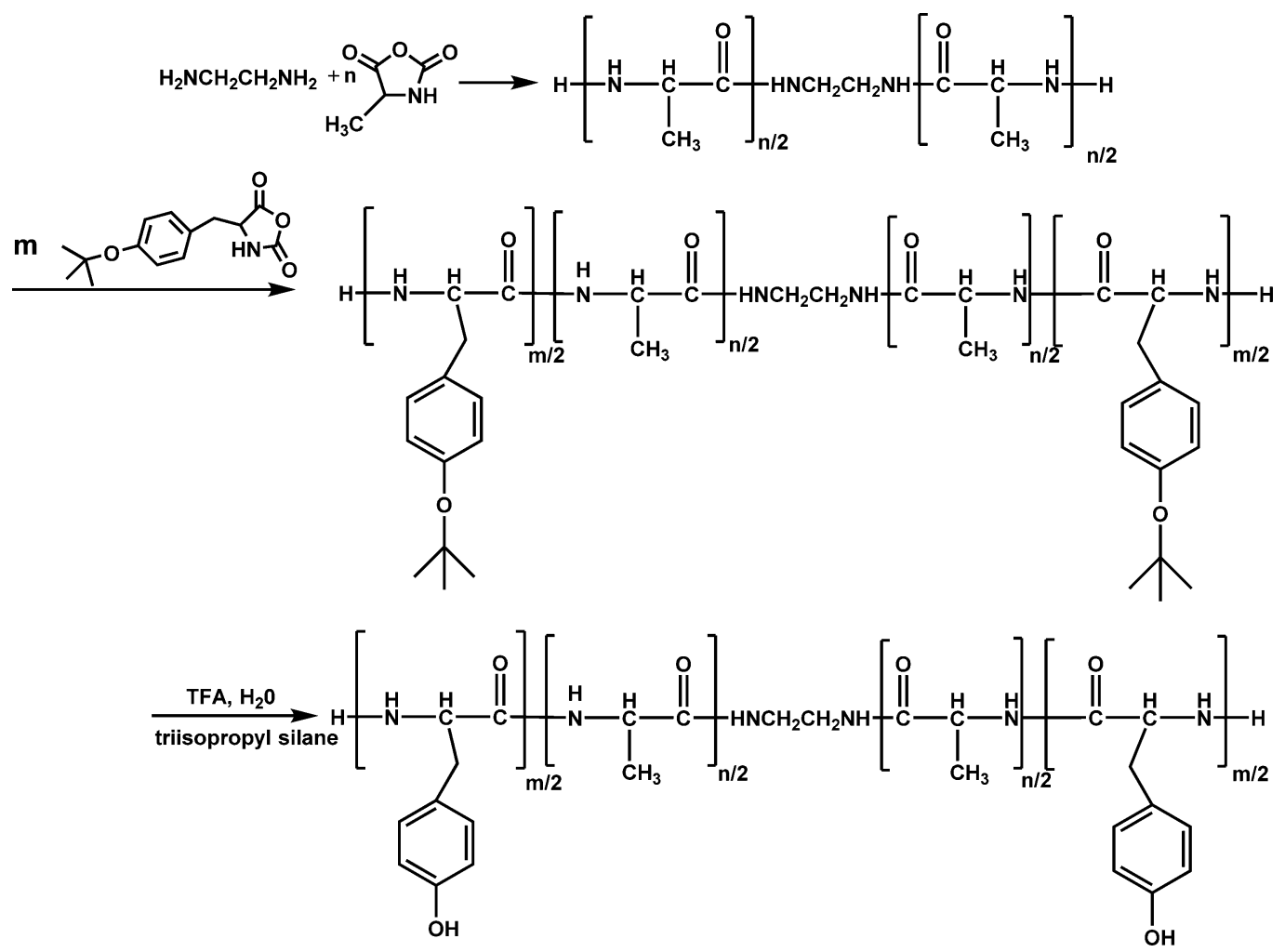




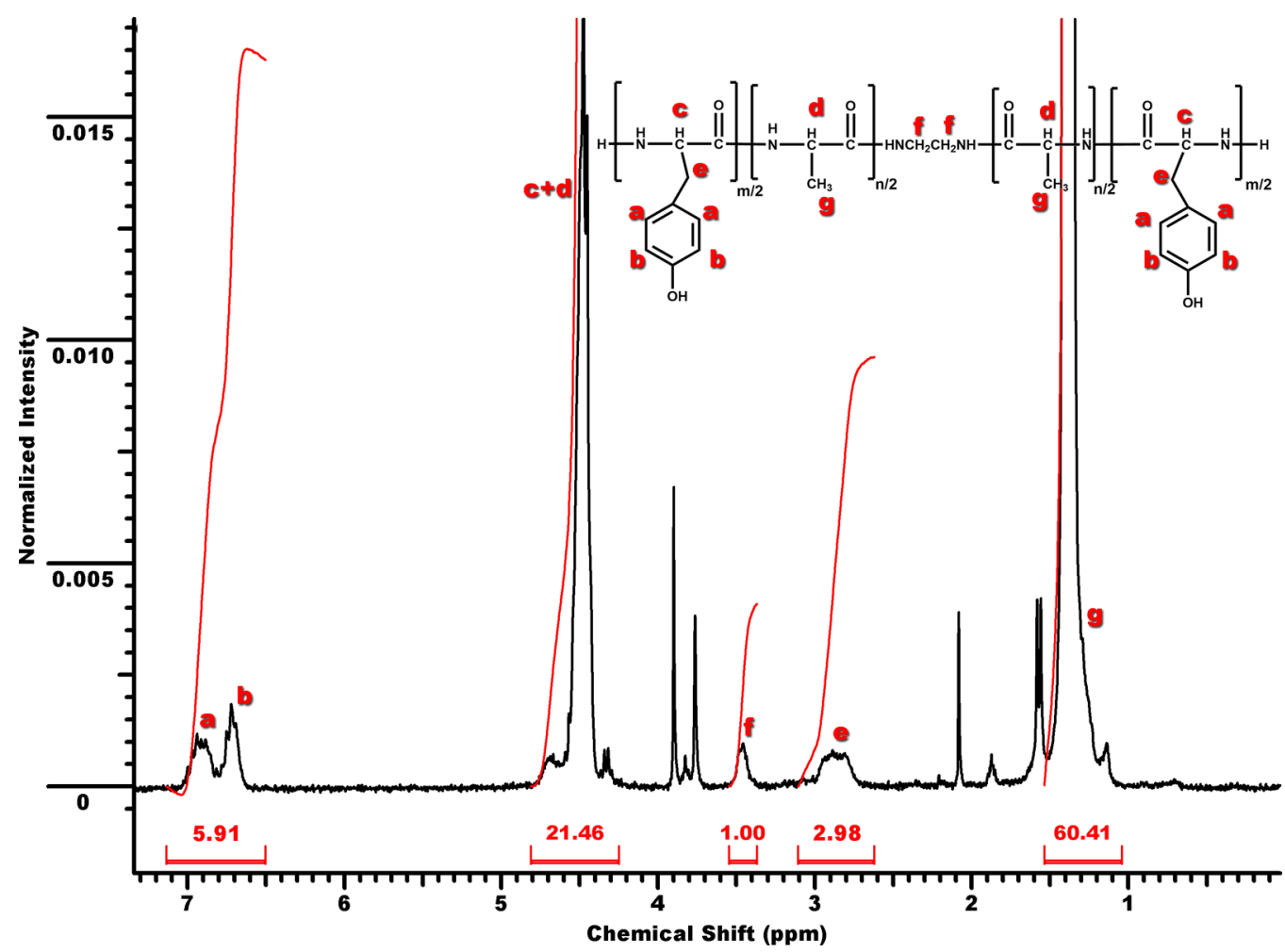

Figure 3. ${ }^{1} \mathrm{H}$ NMR spectrum of the $\mathrm{Tyr}_{3}-\mathrm{PAla}-\mathrm{Tyr}_{3}$ triblock copolymer.

stability heating controller, and a Specac electrical heating jacket. The sample was acclimatized at each temperature point for $10 \mathrm{~min}$ before measurements were taken. Spectra were scanned 128 times over the range of $900-4000 \mathrm{~cm}^{-1}$.

X-ray Diffraction. X-ray diffraction was performed on a peptide stalk prepared by drawing a fiber of $1 \%$ conjugate solution between the ends of wax-coated capillaries, after separation and drying a stalk was left on the end of one capillary. For some samples, the capillary was mounted vertically onto the four axis goniometer of a RAXIS IV++ Xray diffractometer (Rigaku) equipped with a rotating anode generator $\left(\mathrm{CuK}_{\alpha}\right.$ radiation, wavelength $\lambda=1.54 \AA$ ). The XRD data was collected using a Saturn 992 CCD camera. The sample-to-detector distance was $50 \mathrm{~mm}$. Other measurements were performed on stalks mounted (vertically) onto the goniometer of an Oxford Instruments Gemini Xray diffractometer, equipped with a Sapphire 3 CCD detector. The sample to detector distance was $45 \mathrm{~mm}$.

Small-Angle X-ray Scattering. For the solutions, experiments were performed on ID02 at the ESRF, Grenoble France. Samples were flowed through a quartz capillary. After the sample was injected in the capillary and reached the X-ray beam, the flow was stopped during the SAXS data acquisition. The sample-detector distance was $2 \mathrm{~m}$ (data were also obtained at $10 \mathrm{~m}$ ). Data processing (background subtraction, radial averaging) was performed using the dedicated beamline software or SAXSUtilities (http://www.sztucki.de/SAXSutilities/).

For the solid state $\mathrm{Tyr}_{5}-\mathrm{PEO} 6 \mathrm{k}-\mathrm{Tyr}_{5}$ sample, measurements were performed on BM26B (DUBBLE) at the ESRF (Grenoble, France). Time-resolved DSC, SAXS, and WAXS measurements were performed. $^{38,39}$ The sample-to-SAXS detector distance was ca. 1476 $\mathrm{mm}$ using a wavelength of $1.033 \AA$ A. A Dectris-Pilatus $1 \mathrm{M}$ detector with a resolution of $981 \times 1043$ pixels and a pixel size of $172 \times 172$ $\mu \mathrm{m}$ was used to acquire the 2D SAXS scattering patterns. Standard corrections for sample absorption and background subtraction were performed. The data were normalized to the intensity of the incident beam (in order to correct for primary beam intensity fluctuations) and were corrected for absorption and background scattering. Diffraction from silver behenate was used to calibrate the wavevector scale of the scattering curve. WAXS patterns were collected using a Pilatus $300 \mathrm{~K}-$ $\mathrm{W}$ detector (linear, $254 \mathrm{~mm} \times 33.5 \mathrm{~mm}$ active area) with a pixel size of
$172 \mu \mathrm{m}^{2}$. The wavenumber $q=(4 \pi / \lambda) \sin \theta$ scale for the WAXS scale calibration was done using alpha aluminum. The samples were introduced in modified DSC pans pierced in order to produce X-ray windows which were placed in a DSC 600 heating stage from Linkam. The modified DSC pan windows are made of mica, and the capsules were sealed, avoiding sample loss. The sample was heated from -20 to $80{ }^{\circ} \mathrm{C}$ to -20 to $80{ }^{\circ} \mathrm{C}$ at $5{ }^{\circ} \mathrm{C} / \mathrm{min}$, SAXS/WAXS measurements being taken every $30 \mathrm{~s}$.

Rheology. Dynamic shear moduli were measured using a controlled stress AR-2000 rheometer from TA Instruments. A coneand-plate geometry $\left(20 \mathrm{~mm}\right.$ diameter, $1^{\circ}$ angle) was used for a sample of $\mathrm{Tyr}_{5}-\mathrm{PEO}_{\mathrm{k}-\mathrm{Tyr}_{5}}(20 \mathrm{wt} \%$ in water). Stress sweeps were performed first to determine the linear viscoelastic regime. Frequency sweeps were performed with a stress of $4.75 \mathrm{~Pa}$. The angular frequency range was $0.1-622.8 \mathrm{rad} \mathrm{s}^{-1}$, although data are only presented up to $50 \mathrm{rad} \mathrm{s}^{-1}$ due to device inertia at high frequency.

The viscosity of the sample was measured performing varying stress experiments in the range 0.0056 to $16880 \mathrm{~s}^{-1}$.

Polarized Optical Microscopy. Images were obtained with an Olympus BX41 polarized microscope by placing the sample between crossed polarizers. Films were prepared by drying $40 \mu \mathrm{L}$ of 1 wt $\%$ peptide. Dry films were placed between a glass slide and a coverslip before capturing the images with a Canon G2 digital camera.

\section{RESULTS}

The molecular characteristics of the polymers synthesized are shown in Table 1. In the case of the two PEO-containing polymers, the molecular weights were obtained by SECTALLS. The composition of the final copolymers obtained was in excellent agreement with the stoichiometric molecular weights as well as the composition obtained by ${ }^{1} \mathrm{H}$ NMR spectroscopy. The molecular weight of the PTyr-b-PAla- $b$-PTyr copolypeptide was obtained from the ratio of integral of the NMR signal from the protons of the initiator and those of the poly(L-tyrosine) and poly(L-alanine). Due to the low molecular weight of the blocks, it was possible to obtain the accurate 
Table 1. Molecular Characteristics of the Synthesized Polymers

\begin{tabular}{|c|c|c|c|c|c|}
\hline & polymer & $\underset{10^{-3 a}}{M_{\mathrm{n}}(\mathrm{PEO}) \times}$ & $\underset{10^{-3 b}}{M_{\mathrm{n}}(\mathrm{PAl})} \times$ & $\begin{array}{c}M_{\mathrm{n}}(\mathrm{Tyr}) \times \\
10^{-3 c}\end{array}$ & $\begin{array}{c}\text { Tyr units } \\
\pm 1\end{array}$ \\
\hline 1 & $\begin{array}{c}\mathrm{Tyr}_{5}-\mathrm{PEO}_{2 \mathrm{k}}- \\
\mathrm{Tyr}_{5}\end{array}$ & 2.0 & - & 1.70 & $10^{c}$ \\
\hline 2 & $\begin{array}{c}\mathrm{Tyr}_{5}-\mathrm{PEO}_{6 \mathrm{k}}- \\
\mathrm{Tyr}_{5}\end{array}$ & 5.9 & - & 1.75 & $11^{c}$ \\
\hline 3 & $\begin{array}{l}\mathrm{Tyr}_{3} \text {-PAla- } \\
\mathrm{Tyr}_{3}\end{array}$ & - & $5.7 \times 10^{3}$ & 1.00 & $6^{b}$ \\
\hline
\end{tabular}

${ }^{a}$ Obtained by SEC-TALLS. ${ }^{b}$ Obtained by ${ }^{1} \mathrm{H}$ NMR. ${ }^{c}$ Obtained by SEC-TALLS and confirmed with ${ }^{1} \mathrm{H}$ NMR.

molecular weights, which were in good agreement with the stoichiometric ones. This reveals the copolymer contains three tyrosine residues at each terminus, so the polymer is henceforth named $\mathrm{Tyr}_{3}-\mathrm{PAla}-\mathrm{Tyr}_{3}$.

So far, the benzyl protecting group has been used for the synthesis of poly(L-tyrosine) through the NCA approach. ${ }^{40-44}$ The benzyl groups are usually deprotected utilizing $\mathrm{HBr}$ in acetic acid. These conditions are so acidic that almost all protecting groups that are treated under acidic conditions are cleaved, and therefore, these conditions cannot be utilized selectively if an amphiphilic copolypeptide bearing a protected as well as a free residue is to be synthesized. It is well known that the tert-butyl group can be cleaved under mild conditions in the presence of TFA. ${ }^{36}$ Although during the synthesis of the $\mathrm{NCA}$ of tyrosine $\mathrm{HCl}$ is produced, we found that it did not influence the tert-butyl protective group. We found that TFA was an effective reagent to quantitatively remove the tertprotecting group of the hydroxyl group of tyrosine, while, under these conditions, several other protective groups remain intact. Therefore, the novel monomer that we present in this work can be used effectively for the selective deprotection of tyrosine (Supporting Information, Scheme S1).

The secondary structure of the peptide components of the conjugates was examined using a combination of circular dichroism (CD) and FTIR spectroscopy. Figure 4 shows CD spectra. The temperature dependence of the $\mathrm{CD}$ data was examined in the range $20-60^{\circ} \mathrm{C}$, and no significant changes in the CD spectra were noted for either $\mathrm{Tyr}_{5}-\mathrm{PEO} 2 \mathrm{k}-\mathrm{Tyr}_{5}$ or $\mathrm{Tyr}_{5}-\mathrm{PEO} 6 \mathrm{k}-\mathrm{Tyr}_{5}$ (Figure 4a,b). For $\mathrm{Tyr}_{5}-\mathrm{PEO} 6 \mathrm{k}-\mathrm{Tyr}_{5}$ at native $\mathrm{pH}(\mathrm{pH} 5.69)$, the spectra (Figure 4a) show a minimum at $218 \mathrm{~nm}$, which is a signature of $\beta$-sheet structure. The maximum at $228 \mathrm{~nm}$ is due to the absorbance of the tyrosine residues, similar features having been observed for a $\mathrm{Tyr}_{2}-$ PEO1.5k-Tyr 2 conjugate, ${ }^{17}$ YYKLVFF-PEG conjugates with PEG1k or PEG3k, ${ }^{45}$ as well as dityrosine containing peptides. ${ }^{46}$ The spectra for $\mathrm{Tyr}_{5}-\mathrm{PEO} \mathrm{k}^{-} \mathrm{Tyr}_{5}$ at $\mathrm{pH} 12$ (Figure $4 \mathrm{~b}$ ) are qualitatively similar in shape to those at native $\mathrm{pH}$, but with reduced molar ellipticity values pointing to reduced secondary structure content. For $\mathrm{Tyr}_{5}-\mathrm{PEO} 2 \mathrm{k}-\mathrm{Tyr}_{5}$, the spectra shown in Figure $4 \mathrm{c}$ do not extend as low in wavenumber as those for $\mathrm{Tyr}_{5}$-PEO6k-Tyr 5 , due to observed absorption effects but the shape resembles that for the latter conjugate, but with a red shift such that the minimum is at $220 \mathrm{~nm}$ and the maximum due to the tyrosine aromatic units is at $244 \mathrm{~nm}$. The spectra for $\mathrm{Tyr}_{3}-\mathrm{PAla}-\mathrm{Tyr}_{3}$ in Figure $4 \mathrm{~d}$ show a minimum at $226 \mathrm{~nm}$, which can also be assigned to a red-shifted $\beta$-sheet structure. ${ }^{47}$ There is no maximum at higher wavelength due to the tyrosine units, which is presumably because the contribution from these groups is overwhelmed by the poly(L-alanine) midblock with
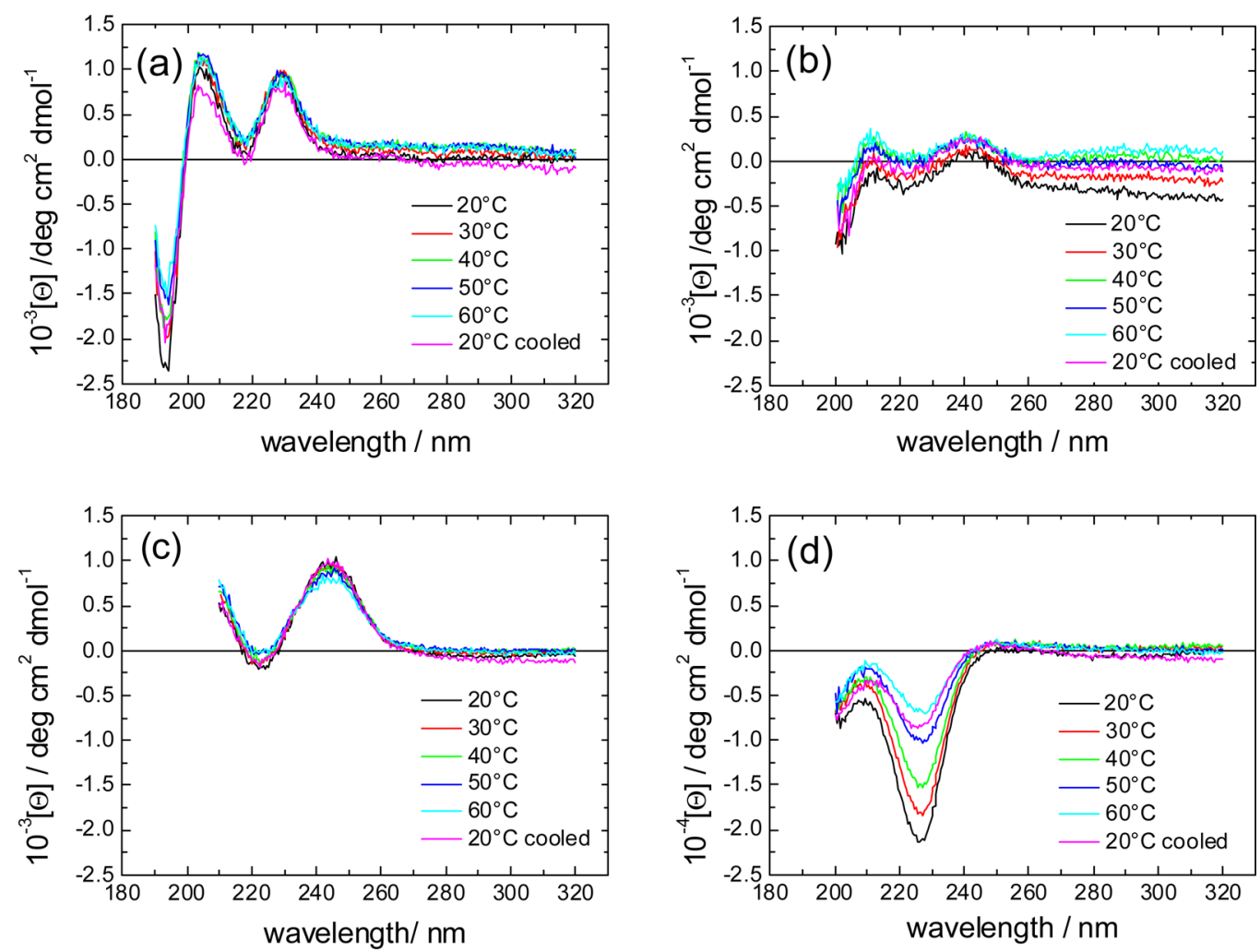

Figure 4. Temperature-dependent CD spectra. (a) $0.1 \mathrm{wt} \% \mathrm{Tyr}_{5}-\mathrm{PEO} \mathrm{k}_{-}-\mathrm{Tyr}_{5}$ (native $\mathrm{pH}=5.69$ ) (b) $0.1 \mathrm{wt} \% \mathrm{Tyr}_{5}-\mathrm{PEO} \mathrm{k}_{-}-\mathrm{Ty}_{\mathrm{r} 5}(\mathrm{pH} 12)$, (c) 0.1 wt $\% \mathrm{Tyr}_{5}-\mathrm{PEO} 2 \mathrm{k}-\mathrm{Tyr}_{5}(\mathrm{pH} 12)$, (d) $0.1 \mathrm{wt} \% \mathrm{Tyr}_{3}-\mathrm{PAla}_{-} \mathrm{Tyr}_{3}(\mathrm{pH} 12)$. Note that the ordinate scale for the spectra in panel $\mathrm{d}$ is $\times 10$ with respect to the other parts. 
approximately 64 alanine repeats. There is a reduction in $\beta$ sheet content on heating leading to a conformational state retained on cooling as the sample approaches its equilibrium state. There is no evidence for helical structure of PAla in the $\mathrm{CD}$ spectra, which is consistent with the analysis of the XRD data (vide infra) from this sample.

The FTIR spectra measured for all three polymers presented in Figure 5 show features in the amide $\mathrm{II}^{\prime}$ region $\left(\mathrm{NH}_{2}\right.$

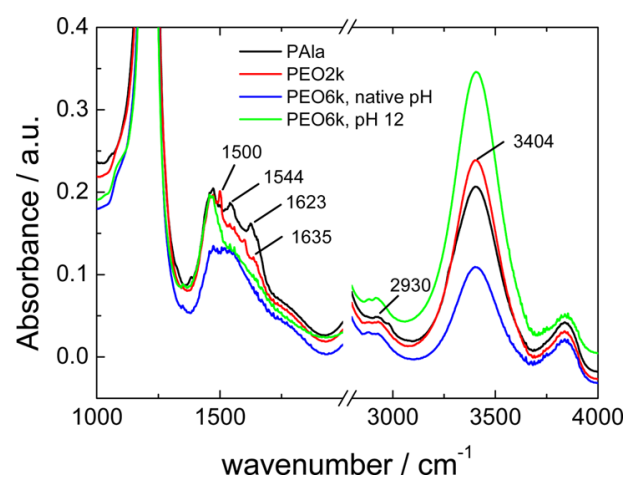

Figure 5. FTIR spectra for 1 wt $\%$ samples. For all samples, the $\mathrm{pH}$ was adjusted to 12 , except where stated.

deformations) around $1500 \mathrm{~cm}^{-1}$ and, most informatively, in the amide $\mathrm{I}^{\prime}$ region which provides information on peptide secondary structure via the $\mathrm{C}=\mathrm{O}$ deformation modes. The spectrum for $\mathrm{Tyr}_{3}-\mathrm{PAla}-\mathrm{Tyr}_{3}$ shows a peak at $1623 \mathrm{~cm}^{-1}$, consistent with the $\beta$-sheet structure of polyalanine-rich peptides (previously observed at $1626 \mathrm{~cm}^{-1}$ for an argininecapped alanine oligomer ${ }^{48}$ ), with a $\beta$-sheet assignment also for the $1635 \mathrm{~cm}^{-1}$ peak for $\mathrm{Tyr}_{5}-\mathrm{PEO} 2 \mathrm{k}-\mathrm{Tyr}_{5}{ }^{49,50}$ For $\mathrm{Tyr}_{5}$ PEO6k- $\mathrm{Tyr}_{5}$, there are no defined peaks in the amide $\mathrm{I}^{\prime}$ region (for samples at either native $\mathrm{pH}$ or at $\mathrm{pH} 12$ ), which prohibits assignment of secondary structure. It is believed that this is due to the absorbance of the longer PEO chain in this compound overwhelming the signal from the peptide end groups. For all samples, the large observed peak near $3400 \mathrm{~cm}^{-1}$ is consistent with $-\mathrm{OH}$ stretch deformations of hydrogen-bonded carbonyl groups in PEO or poly(L-alanine) and the peak at $2930 \mathrm{~cm}^{-1}$ is assigned to $\mathrm{PEO}-\mathrm{CH}_{2}$ or poly(L-alanine) backbone $-\mathrm{CH}$ deformation modes. ${ }^{51}$

Fiber X-ray diffraction on dried stalks was used to investigate the molecular ordering. The fiber X-ray diffraction patterns from all samples were found to be isotropic and were reduced to one-dimensional form. The resulting intensity profiles are shown in Figure 6. These show peaks at 7.49, 5.27, 4.36 and $3.71 \AA$ for $\mathrm{Tyr}_{3}-\mathrm{PAl}_{\mathrm{a}}-\mathrm{Tyr}_{3}$. These are very similar to those we have reported for oligo(alanine) peptides and are assigned to the unusually tightly packed $\beta$-sheet structure of alanine-rich peptides $^{35,48,52}$ with a $\beta$-strand spacing of $4.36 \AA$ and an intersheet spacing of $5.27 \AA$. The XRD data in Figure 6 indicate that there is also $\beta$-sheet content in $\mathrm{Tyr}_{5}-\mathrm{PEO} 2 \mathrm{k}-\mathrm{Tyr}_{5}$, due to the presence of the $4.69 \AA$ reflection, ${ }^{50,53}$ along with some others that are assigned to semicrystalline PEO. That PEO is semicrystalline is shown by the presence of a broad peak due to amorphous polymer, upon which the crystal peaks are superposed. The expected $d$-spacings for the strong reflections (indicated Miller indices) from crystalline PEO $\operatorname{are}^{54} d(\overline{1} 01, \mathrm{~s})$ $=7.89 \AA ⿻ d(101, \mathrm{~s})=5.11 \AA ⿻, d(120, \mathrm{vs})=4.63 \AA, d(\overline{2} 02, \mathrm{~s})=$ $3.94 \AA, d(112)=3.86 \AA, d(031$, vs $)=3.81 \AA$, and $d(\overline{1} 32 / \overline{2} 12$, vs) $=3.79 \AA / 3.78 \AA$. The data for $\mathrm{Tyr}_{5}-\mathrm{PEO} 2 \mathrm{k}-\mathrm{Tyr}_{5}$ are

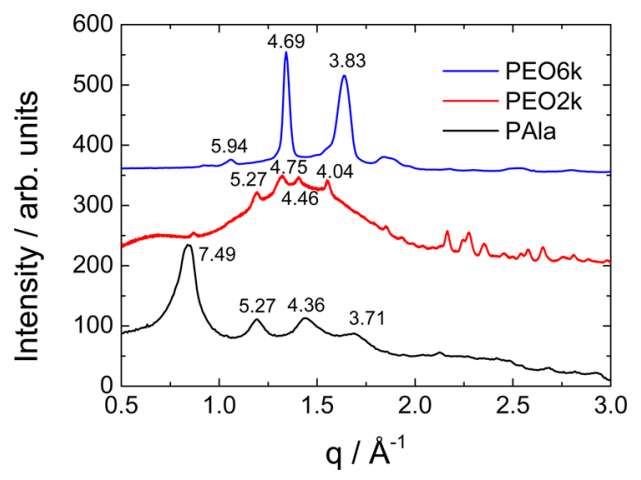

Figure 6. X-ray diffraction data obtained from stalks dried from 1 wt $\%$ solutions, as indicated.

consistent with a very high degree of PEO crystallinity, showing strong peaks at 4.69 and $3.83 \AA$ A. In studies of PEO-peptides comprising KLVFF-based peptides and PEO of different molar mass, we have found that PEO crystallization is modulated by the fibril-forming propensity of the peptide, for instance, in conjugates with a fixed PEO molar mass (PEO3k), crystallization was observed for the weak fibrillizing peptide KLVFF, but not for the strong fibrillizer FFKLVFF. ${ }^{59,56}$ These studies, together with an investigation that compared the structures of FFKLVFF-PEOs with different PEO molar mass $\left(1 \mathrm{k}, 2 \mathrm{k}\right.$, and 10k), ${ }^{57}$ suggest that PEO2k may be close to the molar mass threshold to exhibit some crystallinity. This is consistent with the data in Figure 3 for $\mathrm{Tyr}_{5}-\mathrm{PEO} 2 \mathrm{k}-\mathrm{Tyr}_{5}$, which shows some PEO crystallinity (but to a low extent) along with $\beta$-sheet structure from the $\mathrm{Tyr}_{5}$ end groups. On the other hand, the peaks in the X-ray intensity profiles for $\mathrm{Tyr}_{5}$-PEO6k$\mathrm{Tyr}_{5}$ in Figure 3 are not consistent with $\beta$-sheet order (there is no peak that can be assigned to the $\beta$-sheet stacking distance) and instead can be assigned to peaks from highly crystalline PEO. In fact, there are shifts from the expected peak positions listed above, which is assigned to the influence of the $\mathrm{Tyr}_{5}$ end groups on the PEO unit cell dimensions. A detailed examination of this interesting effect whereby PEO crystallization is modified by the presence of small peptide end groups is outside the scope of the present paper. The findings concerning PEO crystallization for the sample containing PEO6k are consistent with expectations based on the PEO molar mass, and with images of dried films of the samples to be discussed shortly. The same XRD pattern is obtained for stalks dried from $\mathrm{Tyr}_{5}-\mathrm{PEO} \mathrm{k}^{-} \mathrm{Tyr}_{5}$ at native $\mathrm{pH}$ or at $\mathrm{pH} 12$ (data not shown).

Cryo-TEM was used to image self-assembled nanostructure. Figure 7 shows representative images. For $\mathrm{Tyr}_{5}-\mathrm{PEO} 6 \mathrm{k}-\mathrm{Tyr}_{5}$, the presence of short, very straight fibrils approximately $5 \mathrm{~nm}$ in diameter extending to a few hundred $\mathrm{nm}$ in length is clear, these coexisting with shorter (and nearly spherical) nanostructures of similar diameter. For $\mathrm{Tyr}_{5}-\mathrm{PEO} 2 \mathrm{k}-\mathrm{Tyr}_{5}$, cryo-TEM reveals clusters of short fibrils. SAXS data (Figure 8) clearly supports the presence of fibrillar structures. A similar structure of local clusters of fine fibrils/filaments was also observed for $\mathrm{Tyr}_{3}$-PAla-Tyr ${ }_{3}$. These observations are consistent with the presence of $\beta$-sheet structures (which are typically present in extended fibrils) for these samples, as revealed by spectroscopic methods, as discussed above. The difference in appearance of the fibrils of $\mathrm{Tyr}_{5}-\mathrm{PEO} 6 \mathrm{k}-\mathrm{Tyr}_{5}$ is striking as they are extremely straight. Similar straight fibrils have previously been observed for $\mathrm{Phe}_{4}-\mathrm{PEO} 5 \mathrm{k}^{58}$ and suggest that such short straight fibrils are 

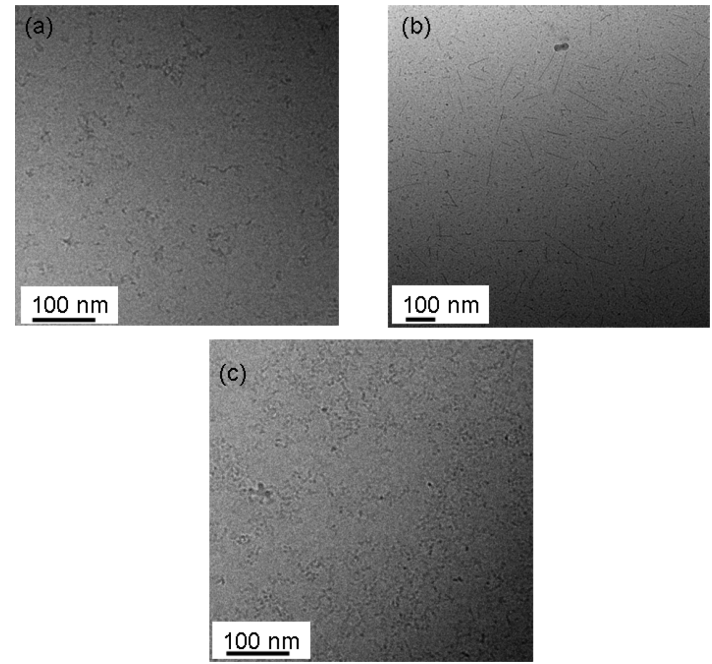

Figure 7. Cryo-TEM images. (a) $\mathrm{Tyr}_{5}-\mathrm{PEO} 2 \mathrm{k}-\mathrm{Tyr}_{5}$ ( $\mathrm{pH}$ 12), (b) $\mathrm{Tyr}_{5}$-PEO6k-Tyr ${ }_{5}$ (native $\mathrm{pH}$ ), (c) $\mathrm{Tyr}_{3}$-PAla-Tyr 3 (pH 12).
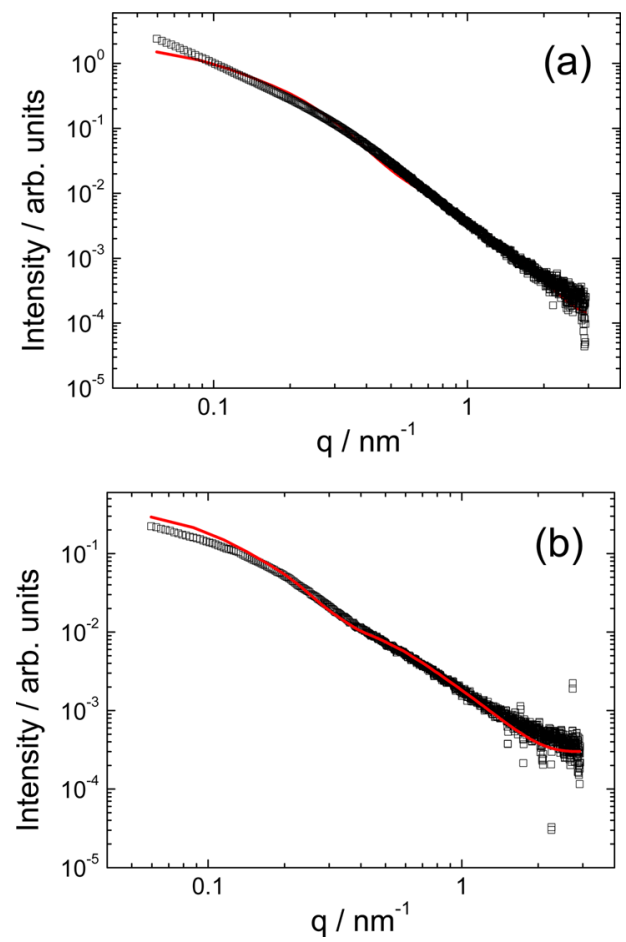

Figure 8. SAXS data obtained for $1 \mathrm{wt} \%$ solutions of (a) $\mathrm{Tyr}_{5}$-PEO2k$\mathrm{Tyr}_{5}$ and (b) $\mathrm{Ty}_{\mathrm{r} 5}$-PEO6k-Tyr $\mathrm{P}_{5}$ (native $\mathrm{pH}$ ). Open squares: measured data; red lines: form factor fits using a cylindrical shell model.

favored when the PEO chain length is in the range PEO5kPEO6k, whereas more flexible fibrils, also termed "wormlike micelles", are observed for diblock conjugates of PEO (molar mass $0.5-1.8 \mathrm{~kg} \mathrm{~mol}^{-1}$ ) to $\mathrm{Phe}_{4}{ }^{59}$
Small-angle X-ray scattering measurements were performed to provide further information on the dimensions of the cylindrical fibrils. The measured data along with form factor fits are shown in Figure 8. The data were fitted to a cylindrical core-shell form factor since there is a noticeable change in slope of the intensity profiles near $\mathrm{q}=0.3 \AA^{-1}$. The fit parameters are listed in Table 2 . The core radius for both $\mathrm{Tyr}_{5}-$ PEO2k-Tyr 5 and $\mathrm{Tyr}_{5}-\mathrm{PEO6k-Tyr_{5 }}$ is $R=1.03 \mathrm{~nm}$ and $R=$ $2.28 \mathrm{~nm}$ respectively, which is consistent with the core comprising $\mathrm{Tyr}_{5}$ plus some of the inner part of the PEO chains, since the estimated length of a $\mathrm{Tyr}_{5}$ sequence in a $\beta$ strand is $5 \times 0.32 \mathrm{~nm}=1.6 \mathrm{~nm}$ only (using the $3.2 \AA$ translation per residue expected for a parallel $\beta$-sheet structure $\left.^{37}\right)$. This radius is consistent with that estimated

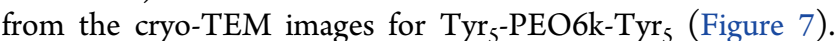
As expected, the shell radius is lower for $\mathrm{Tyr}_{5}-\mathrm{PEO} 2 \mathrm{k}-\mathrm{Tyr}_{5}$ compared to $\mathrm{Tyr}_{5}-\mathrm{PEO} 6 \mathrm{k}-\mathrm{Tyr}_{5}(\Delta R=1.92$ vs $2.20 \mathrm{~nm})$. The estimated radius of gyration of PEO6k is $R_{\mathrm{g}}=2.6 \mathrm{~nm}$ and of PEO2k is $R_{\mathrm{g}}=1.5 \mathrm{~nm}$ (based on a segment length $b=5.6$ $\AA{ }^{60-62}$ Hammouda and Ho report $b=5.8 \AA^{63}$ ). The values of $\Delta R$ from the core-shell cylinder form factor fit are close to these values, but are not identical due to the fact that the core radius $R$ includes some of the inner PEO chains, as mentioned above, and there may also be some expansion of the PEO2k chains, in particular in the fibril corona.

We also examined possible gel formation by inspection of samples, followed by shear rheometry of concentrated liquids. It was observed that neither $\mathrm{Tyr}_{5}-\mathrm{PEO} \mathrm{k}^{-} \mathrm{Tyr}_{5}$ (native $\mathrm{pH}$ or $\mathrm{pH}$ 12) nor $\mathrm{Tyr}_{5}-\mathrm{PEO} 2 \mathrm{k}-\mathrm{Tyr}_{5}$ form a gel up to $20 \mathrm{wt} \%$ (sample $\mathrm{Tyr}_{3}-\mathrm{PAla}-\mathrm{Tyr}_{3}$ is not soluble at high concentration so gel formation is precluded). Figure 9 shows measurements of
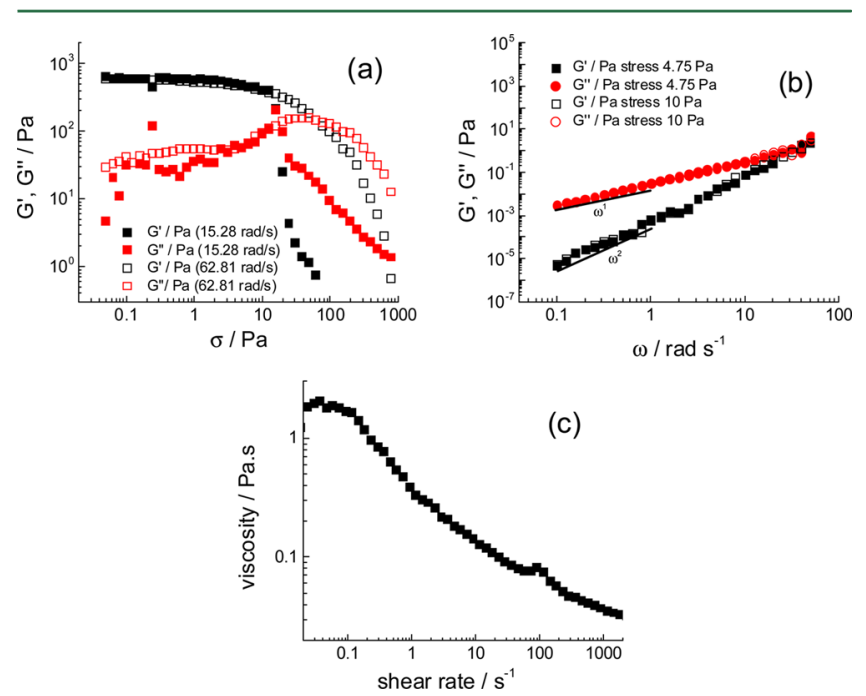

Figure 9. Dynamic shear modulus measured for a $20 \mathrm{wt} \%$ solution of $\mathrm{Tyr}_{5}$-PEO6k-Tyr $\mathrm{F}_{5}$ (native $\mathrm{pH}$ ): (a) stress sweeps at two angular frequencies, $\omega$, indicated; (b) frequency sweep at two stress values indicated. (c) Shear rate dependence of the viscosity.

\section{Table 2. SAXS Form Factor Fit Parameters ${ }^{a}$}

\begin{tabular}{|c|c|c|c|c|c|c|c|c|c|}
\hline sample & $N$ & $\sigma / \mathrm{nm}$ & $\mathrm{R} / \mathrm{nm}$ & $\Delta \mathrm{R} / \mathrm{nm}$ & $L / \mathrm{nm}$ & $\eta($ core $)$ & $\eta($ shell $)$ & $\eta($ solv $)$ & BG \\
\hline PEO2k & 0.06 & 2.48 & 1.03 & 1.92 & 50 & $1.6 \times 10^{-5}$ & $-7.1 \times 10^{-4}$ & $2.4 \times 10^{-4}$ & $1.3 \times 10^{-4}$ \\
\hline PEO6k & 0.015 & 2.66 & 2.28 & 2.20 & 50 & $4.1 \times 10^{-4}$ & $-1.7 \times 10^{-3}$ & $1.0 \times 10^{-4}$ & $3 \times 10^{-4}$ \\
\hline
\end{tabular}

${ }^{a}$ The fit was performed using the long cylindrical shell form factor using software SASfit. ${ }^{72} \mathrm{~N}=$ scaling factor. $\sigma=$ Gaussian polydispersity parameter. $R=$ cylinder radius. $\Delta \mathrm{R}=$ shell thickness. $L=$ Length of cylinder (fixed). $\eta($ core $)=$ scattering length density of core. $\eta$ (shell) $=$ scattering length density of shell. $\eta($ solv $)=$ scattering length density of solvent. BG = background (fixed). 
dynamic shear modulus for a viscous $20 \mathrm{wt} \%$ solution of $\mathrm{Tyr}_{5}-$ PEO6k- $\mathrm{Tyr}_{5}$. Stress sweeps (Figure 9a) showed approximately linear viscoelastic behavior up to a stress $\sigma=10 \mathrm{~Pa}$. Frequency sweeps were then performed, and the results at two different stress values are shown in Figure 9b. These reveal frequencydependent moduli $G^{\prime \prime}>G^{\prime}$ (and low values of both moduli) consistent with a predominantly fluid-like response. This conclusion is supported by the observed terminal scalings of the moduli $G^{\prime} \sim \omega^{2}$ and $G^{\prime \prime} \sim \omega^{1} .{ }^{64}$ The lack of observed gel formation by $\mathrm{Tyr}_{5}-\mathrm{PEO} 6 \mathrm{k}-\mathrm{Tyr}_{5}$ even with conjugate concentration up to $20 \mathrm{wt} \%$ in aqueous solution may be contrasted with the prior observation of hydrogel formation (at $6 \mathrm{wt} \%$ ) by $\mathrm{NH}_{2}-\mathrm{Tyr}_{2}$-PEO1.5k-Tyr 2 -Fmoc; ${ }^{17}$ however, the Fmoc (Nfluorenyl-9-methoxycarbonyl) unit has a substantial influence on the hydrophobicity of this conjugate and hence on its ability to form a hydrogel. Also hydrogel formation has been observed for a 10 wt \% solution of PAla-PGlu-PAla [PGlu: poly(Lglutamic acid)] in buffer solution ${ }^{31}$ although this has a charged midblock and different block sequence to our conjugates. Figure $9 \mathrm{c}$ shows the shear rate dependence of the viscosity for the $\mathrm{Tyr}_{5}-\mathrm{PEO} 6 \mathrm{k}-\mathrm{Tyr}_{5}$ conjugate. This shows a Newtonian regime up to approximately $\dot{\gamma}=0.1 \mathrm{~s}^{-1}$, followed by a shearthinning regime with an initial power-law Ostwald-de Waele ${ }^{65}$ behavior, $\eta \sim \dot{\gamma}^{-0.5}$. Similar shear-thinning behavior is observed for conventional associative polymers and solutions of wormlike micelles. ${ }^{64}$

As well as examining the self-assembly of the conjugates in aqueous solution, the behavior of the $\mathrm{Tyr}_{5}$-PEO6k-Tyr 5 sample that exhibits PEO6k crystallization on drying was investigated in more detail in the solid state. Figure 10 shows results from synchrotron SAXS/WAXS samples on a dry sample. SAXS and WAXS (Figure 10a,b) show that the first melting of PEO occurs at $52{ }^{\circ} \mathrm{C}$, which is a typical value for the melting temperature $T_{\mathrm{m}}$ for PEO with a molar mass of $6 \mathrm{~kg} \mathrm{~mol}^{-1}{ }^{66} \mathrm{On}$ cooling, crystallization is observed to start at $50{ }^{\circ} \mathrm{C}$ and the second melting at $52{ }^{\circ} \mathrm{C}$. These results indicate a low degree of hysteresis in the melting/crystallization behavior. After the second crystallization, the SAXS data (Figure 10c) shows a broad peak centered at $q^{*}=0.5 \mathrm{~nm}^{-1}$ consistent with the presence of crystalline lamellae, ${ }^{67-69}$ but there was no evidence for microphase separation in the melt state. The crystalline lamellar period is $12.6 \mathrm{~nm}$, which indicates significant extension of the PEO chains compared to the conformation in aqueous solution discussed above. Actually, the chain length of PEO in $\mathrm{Tyr}_{5}-\mathrm{PEO6k-Tyr}{ }_{5}$ can be estimated as $l=0.095 z_{\mathrm{EO}}$ where 0.095 $\AA$ is the length per atom along the PEO helix and $z_{\mathrm{EO}}$ is the number of atoms ${ }^{70}$ (here $136 \times 3$, where $N=136$ is the degree of polymerization), yielding $l=38.8 \mathrm{~nm}$. Comparison of this to the measured value of the crystal period points to chain folding of the PEO. Figure 10d shows the WAXS profile in the crystalline state for comparison to the fiber XRD data shown in Figure 6.

These findings concerning PEO crystallization were supported by polarized optical microscopy (POM) images from dried films, shown in Figure 11. For $\mathrm{Tyr}_{5}-\mathrm{PEO} 6 \mathrm{k}-\mathrm{Tyr}_{5}$, under native $\mathrm{pH}$ conditions there is clear evidence for the presence of crystal spherulites for the dried sample whereas the sample dried from $\mathrm{pH} 12$ exhibits much smaller and less extensive crystallites. Partial crystallinity with poorly developed spherulites was observed for $\mathrm{Tyr}_{5}-\mathrm{PEO} 2 \mathrm{k}-\mathrm{Tyr}_{5}$ at $\mathrm{pH}$ 12, consistent with the WAXS data.
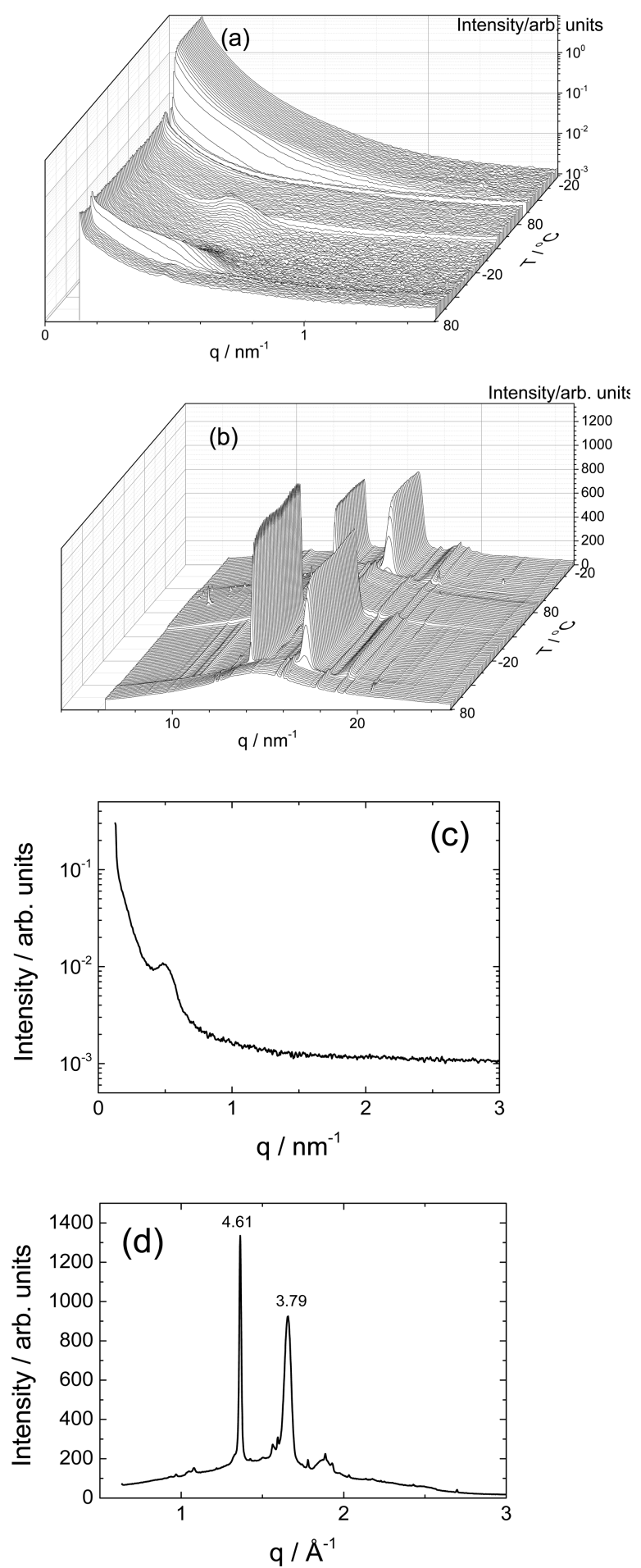

Figure 10. Simultaneous synchrotron X-ray scattering from $\mathrm{Tyr}_{5}$ PEO6k- $\mathrm{Tyr}_{5}$ in the solid state: (a) temperature ramp SAXS data, (b) simultaneous temperature ramp WAXS data, (c) SAXS data on first cooling at $18{ }^{\circ} \mathrm{C}$, and (d) WAXS data on first cooling at $18{ }^{\circ} \mathrm{C}$.

\section{SUMMARY AND CONCLUSIONS}

All three oligo(tyrosine)-polymer-oligo(tyrosine) conjugates self-assemble into $\beta$-sheet fibrillar structures as shown by a combination of spectroscopic, scattering and microscopy methods. The amide I' FTIR spectrum for $\mathrm{Tyr}_{5}-\mathrm{PEO} 6 \mathrm{k}-\mathrm{Tyr}_{5}$ did not show the typical peak for $\beta$-sheet structure (probably due to the dominant contribution from unordered PEO6k), but 


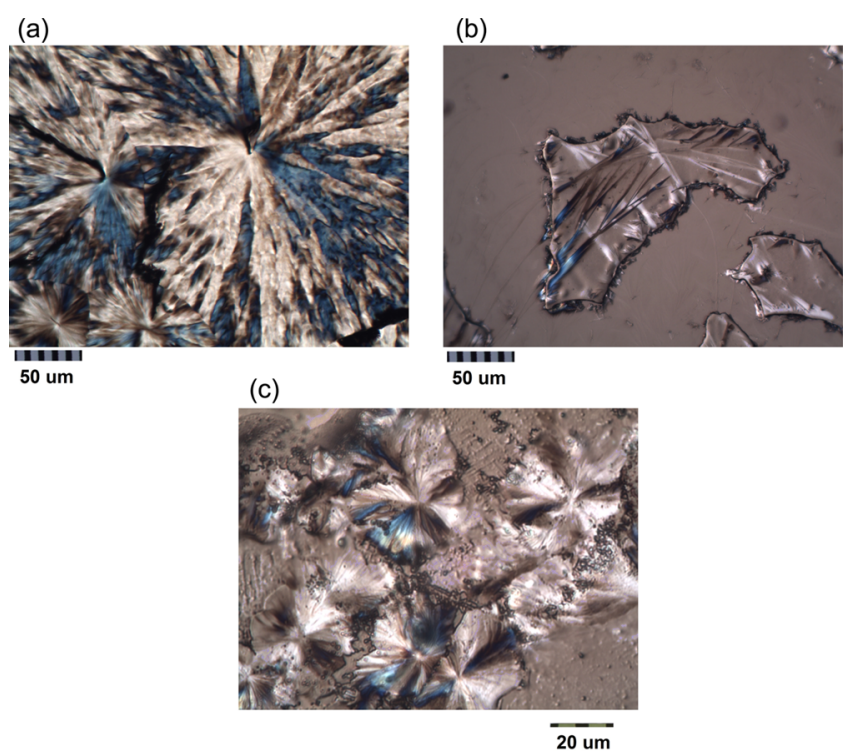

Figure 11. Polarized optical microscopy images of dried samples. (a) $\mathrm{Tyr}_{5}$-PEO6k-Tyr $\mathrm{r}_{5}$, native $\mathrm{pH},(\mathrm{b}) \mathrm{Tyr}_{5}-\mathrm{PEO} \mathrm{k}^{-} \mathrm{Tyr}_{5}, \mathrm{pH}$ 12, (c) $\mathrm{Tyr}_{5}-$ PEO2k-Tyr ${ }_{5}, \mathrm{pH} 12$.

the $\mathrm{CD}$ data confirmed the assignment of this structure. The $\mathrm{CD}$ spectra for this sample and the $\mathrm{Tyr}_{5}-\mathrm{PEO} 2 \mathrm{k}-\mathrm{Tyr}_{5}$ sample contain peaks also from the $\mathrm{Tyr}_{5}$ end groups. The SAXS and cryo-TEM data provide clear evidence for the formation of fibrillar structures. A schematic of the proposed fibrillar structure is shown in Figure 12. One remarkable result from

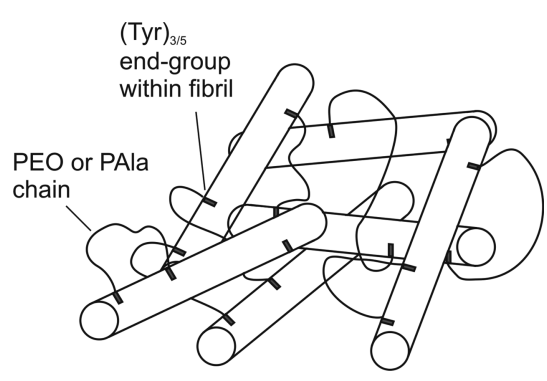

Figure 12. Schematic self-assembled structure showing tyrosine fibrillar network linked by PEO or PAla chains with bridging and looping conformations.

our study is that even polymers with end-groups as short as three tyrosine residues can self-assemble to form tyrosine fibrils. The self-assembly of the $\mathrm{Tyr}_{3}-\mathrm{PAla}-\mathrm{Tyr}_{3}$ conjugate is significantly influenced by the PAla secondary structure and as discussed above oligo- or poly-(L-alanine) adopts a very interesting tightly packed $\beta$-sheet structure with a substantially smaller intersheet spacing and interstrand spacing than formed by peptides containing larger side groups. For $\mathrm{Tyr}_{5}$-PEO6k$\mathrm{Tyr}_{5}$ the presence of the longer PEO chain compared to that in $\mathrm{Tyr}_{5}-\mathrm{PEO} 2 \mathrm{k}-\mathrm{Tyr}_{5}$ enables dissolution in water at native $\mathrm{pH}$ rather than above the tyrosine $\mathrm{p} K_{\mathrm{a}}\left(\mathrm{p} K_{\mathrm{a}}=10.1^{37}\right)$; however, interestingly, this has little difference on the observed secondary structure formation.

The fibril morphology is distinct comparing the two PEObased conjugates; whereas irregular clusters of short flexible fibers are observed for $\mathrm{Tyr}_{5}-\mathrm{PEO} 2 \mathrm{k}-\mathrm{Tyr}_{5}$, the conjugate with PEO6k self-assembles to form a population of very straight and well-defined (narrow dispersity in width) fibrils. This difference in morphology is consistent with prior reports on the formation of straight fibril-like structures in "diblock" polymer/peptide conjugates with PEO molar mass around $5 \mathrm{k}^{58,59}$ In the present conjugates, which differ in having a telechelic "triblock" architecture, the longer PEO chain will have greater conformational flexibility, which may have several effects: (i) The greater PEO chain flexibility may enable tighter packing of the Tyr endgroups in the fibril reducing the tendency for fibril curvature; (ii) It may permit more looped conformations, which could act to stabilize short straight fibrils via coverage of fibril sides (reducing fibril width dispersity) or ends (preventing very long fibrils from assembling).

The presence of PEO means that PEO crystallization can occur upon drying. Indeed, the XRD pattern for $\mathrm{Tyr}_{5}$-PEO6k$\mathrm{Tyr}_{5}$ is dominated by strong peaks from crystalline PEO, whereas $\mathrm{Tyr}_{5}-\mathrm{PEO} 2 \mathrm{k}-\mathrm{Tyr}_{5}$ contains a substantial amorphous fraction in the solid state. The SAXS pattern for $\mathrm{Tyr}_{5}$-PEO6k$\mathrm{Tyr}_{5}$ in the solid state contains a peak due to the formation of semicrystalline PEO lamellae. These findings are supported by observation of the spherulites formed in dried films of these samples, which are extensive and sample-spanning for $\mathrm{Tyr}_{5}$ PEO6k- $\mathrm{Tyr}_{5}$ but not $\mathrm{Tyr}_{5}-\mathrm{PEO} 2 \mathrm{k}-\mathrm{Tyr}_{5}$.

This manuscript reports a comprehensive study of the selfassembly of these telechelic conjugates capped with short tyrosine blocks. In future work, it will be interesting to examine the bioactivity and potential cytocompatibility of these conjugates resulting from the tyrosine functionality or to investigate responsiveness, induced for example by enzymatic triggering of tyrosine phosphorylation using kinases. Tyrosine phosphorylation plays an important role in many cell signaling processes, and there is the scope to develop novel biomaterials to tune cell signaling processes based on polymer/tyrosine conjugates. In a similar vein, it will also be interesting to explore the conditions where (hydro)gelation can be induced.

\section{ASSOCIATED CONTENT}

\section{S Supporting Information}

The Supporting Information is available free of charge on the ACS Publications website at DOI: 10.1021/acs.biomac.6b00023.

Reaction scheme for the Tyrosine NCA, ${ }^{1} \mathrm{H}$ NMR spectrum of the novel monomer $\operatorname{Tyr}(\mathrm{tBu})-\mathrm{NCA}$, and FTIR spectra monitoring the synthesis of the $\mathrm{Tyr}(\mathrm{tBu})$ NCA (PDF)

\section{AUTHOR INFORMATION}

\section{Notes}

The authors declare no competing financial interest.

\section{ACKNOWLEDGMENTS}

This work was supported by an STFC Futures Studentship (ST/L502480/1) that supported the work of S.K. and EPSRC Platform Grant EP/L020599/1. We are grateful to the ESRF (Grenoble, France) for the award of beamtime on ID02 (ref SC-4063) and to Theyencheri Narayanan for assistance. Use of facilities in the Chemical Analysis Facility at the University of Reading is gratefully acknowledged.

\section{REFERENCES}

(1) Schlaad, H. Solution properties of polypeptide-based copolymers. Adv. Polym. Sci. 2006, 202, 53-73. 
(2) Heredia, K. L.; Maynard, H. D. Synthesis of protein-polymer conjugates. Org. Biomol. Chem. 2007, 5, 45-53.

(3) Canalle, L. A.; Löwik, D. W. P. M.; van Hest, J. C. M. Polypeptide-polymer bioconjugates. Chem. Soc. Rev. 2010, 39, 329353.

(4) Nicolas, J.; Mantovani, G.; Haddleton, D. M. Living radical polymerization as a tool for the synthesis of polymer-protein/peptide bioconjugates. Macromol. Rapid Commun. 2007, 28, 1083-1111.

(5) Gauthier, M. A.; Klok, H. A. Peptide/protein-polymer conjugates: synthetic strategies and design concepts. Chem. Commun. 2008, 25912611.

(6) Klok, H. A. Peptide/protein - synthetic polymer conjugates. Macromolecules 2009, 42, 7990-8000.

(7) Rabotyagova, O. S.; Cebe, P.; Kaplan, D. L. Protein-Based Block Copolymers. Biomacromolecules 2011, 12, 269-289.

(8) Hamley, I. W. PEG-Peptide Conjugates. Biomacromolecules 2014, $15,1543-1559$.

(9) Hamley, I. W.; Krysmann, M. J.; Castelletto, V.; Kelarakis, A.; Noirez, L.; Hule, R. A.; Pochan, D. Nematic and columnar ordering of a PEG-peptide conjugate in aqueous solution. Chem. - Eur. J. 2008, 14, 11369-11374.

(10) Hamley, I. W.; Krysmann, M. J.; Castelletto, V.; Noirez, L. Multiple Lyotropic Polymorphism of a PEG-Peptide Diblock Copolymer in Aqueous Solution. Adv. Mater. 2008, 20, 4394-4397.

(11) Hamley, I. W.; Krysmann, M. J.; Newby, G. E.; Castelletto, V.; Noirez, L. Orientational Ordering in the Nematic Phase of a PEGPeptide Conjugate in Aqueous Solution. Phys. Rev. E 2008, 77, 062901.

(12) Petka, W. A.; Harden, J. L.; McGrath, K. P.; Wirtz, D.; Tirrell, D. A. Reversible hydrogels from self-assembling artificial proteins. Science 1998, 281, 389-392.

(13) Shen, W.; Zhang, K.; Kornfield, J. A.; Tirrell, D. A. Tuning the erosion rate of artificial protein hydrogels through control of network topology. Nat. Mater. 2006, 5, 153-158.

(14) Tzokova, N.; Fernyhough, C. M.; Topham, P. D.; Sandon, N.; Adams, D. J.; Butler, M. F.; Armes, S. P.; Ryan, A. J. Soft Hydrogels from Nanotubes of Poly(ethylene oxide) -Tetraphenylalanine Conjugates Prepared by Click Chemistry. Langmuir 2009, 25, 2479-2485.

(15) Jing, P.; Rudra, J. S.; Herr, A. B.; Collier, J. H. Self-assembling peptide-polymer hydrogels designed from the coiled coil region of fibrin. Biomacromolecules 2008, 9, 2438-2446.

(16) Stahl, P. J.; Romano, N. H.; Wirtz, D.; Yu, S. M. PEG-Based Hydrogels with Collagen Mimetic Peptide-Mediated and Tunable Physical Cross-Links. Biomacromolecules 2010, 11, 2336-2344.

(17) Hamley, I. W.; Cheng, G.; Castelletto, V. Self-Assembly of Telechelic PEG End-capped with Hydrophobic Dipeptides. Macromol. Biosci. 2011, 11, 1068-1078.

(18) Annable, T.; Buscall, R.; Ettelaie, R; Whittlestone, D. The rheology of solutions of associating polymers: Comparison of experimental behavior with transient network theory. J. Rheol. 1993, $37,695-726$.

(19) Winnik, M. A.; Yekta, A. Associative polymers in aqueous solution. Curr. Opin. Colloid Interface Sci. 1997, 2, 424.

(20) Hamley, I. W. Block Copolymers in Solution; Wiley: Chichester, U.K., 2005.

(21) Pilkington-Miksa, M. A.; Sarkar, S.; Writer, M. J.; Barker, S. E.; Shamlou, P. A.; Hart, S. L.; Hailes, H. C.; Tabor, A. B. Synthesis of bifunctional integrin-binding peptides containing PEG spacers of defined length for non-viral gene delivery. Eur. J. Org. Chem. 2008, 2008, 2900-2914.

(22) Dekker, F. J.; de Mol, N. J.; van Ameijde, J.; Fischer, M. J. E.; Ruijtenbeek, R.; Redegeld, F. A. M.; Liskamp, R. M. J. Replacement of the intervening amino acid sequence of a Syk-binding diphosphopeptide by a nonpeptide spacer with preservation of high affinity. ChemBioChem 2002, 3, 238-242.

(23) Olsen, B. D.; Kornfield, J. A.; Tirrell, D. A. Yielding Behavior in Injectable Hydrogels from Telechelic Proteins. Macromolecules 2010, 43, 9094-9099.
(24) Skrzeszewska, P. J.; Jong, L. N.; de Wolf, F. A.; Cohen Stuart, M. A.; van der Gucht, J. Shape-Memory Effects in Biopolymer Networks with Collagen-Like Transient Nodes. Biomacromolecules 2011, 12, 2285-2292.

(25) Cingil, H. E.; Rombouts, W. H.; van der Gucht, J.; Cohen Stuart, M. A.; Sprakel, J. Equivalent Pathways in Melting and Gelation of Well-Defined Biopolymer Networks. Biomacromolecules 2015, 16, 304-310.

(26) Skrzeszewska, P. J.; de Wolf, F. A.; Werten, M. W. T.; Moers, A.; Cohen Stuart, M. A.; van der Gucht, J. Physical gels of telechelic triblock copolymers with precisely defined junction multiplicity. Soft Matter 2009, 5, 2057-2062.

(27) Julich-Gruner, K. K.; Neffe, A. T.; Lendlein, A. Synthesis and characterization of oligo(ethylene glycol)s functionalized with desaminotyrosine or desaminotyrosyltyrosine. J. Appl. Biomater. Funct. Mater. 2012, 10, 170-176.

(28) Zaupa, A.; Neffe, A. T.; Pierce, B. F.; Noechel, U.; Lendlein, A. Influence of Tyrosine-Derived Moieties and Drying Conditions on the Formation of Helices in Gelatin. Biomacromolecules 2011, 12, 75-81.

(29) Neffe, A. T.; Zaupa, A.; Pierce, B. F.; Hofmann, D.; Lendlein, A. Knowledge-Based Tailoring of Gelatin-Based Materials by Functionalization with Tyrosine-Derived Groups. Macromol. Rapid Commun. 2010, 31, 1534-1539.

(30) Hua, S. H.; Li, Y. Y.; Liu, Y.; Xiao, W.; Li, C.; Huang, F. W.; Zhang, X. Z.; Zhuo, R. X. Self-Assembled Micelles Based on PEGPolypeptide Hybrid Copolymers for Drug Delivery. Macromol. Rapid Commun. 2010, 31, 81-86.

(31) Popescu, M. T.; Liontos, G.; Avgeropoulos, A.; Tsitsilianis, C. Stimuli responsive fibrous hydrogels from hierarchical self-assembly of a triblock copolypeptide. Soft Matter 2015, 11, 331-342.

(32) Black, S. D.; Mould, D. R. Development of hydrophobicity parameters to analyze proteins which bear post- or cotranslational modifications. Anal. Biochem. 1991, 193, 72-82.

(33) White, S. H.; Wimley, W. C. Membrane protein folding and stability: Physical principles. Annu. Rev. Biophys. Biomol. Struct. 1999, 28, 319-365.

(34) Kyte, J.; Doolittle, R. F. A Simple Method For Displaying the Hydropathic Character of a Protein. J. Mol. Biol. 1982, 157, 105-132.

(35) Hamley, I. W.; Kirkham, S.; Dehsorkhi, A.; Castelletto, V.; Adamcik, J.; Mezzenga, R.; Ruokolainen, J.; Mazzuca, C.; Gatto, E.; Venanzi, M.; Placidi, E.; Bilalis, P.; Iatrou, H. Self-Assembly of a Model Peptide Incorporating a Hexa-Histidine Sequence Attached to an Oligo-Alanine Sequence, and Binding to Gold NTA/Nickel Nanoparticles. Biomacromolecules 2014, 15, 3412-3420.

(36) Wuts, P. G. M.; Greene, T. W. Greene's Protective Groups in Organic Synthesis, 4th ed.; Wiley: New York, 2007.

(37) Creighton, T. E. Proteins: Structures and Molecular Properties; W.H.Freeman: New York, 1993.

(38) Bras, W.; Dolbnya, I. P.; Detollenaere, D.; van Tol, R.; Malfois, M.; Greaves, G. N.; Ryan, A. J.; Heeley, E. Recent experiments on a combined small-angle/wide-angle X-ray scattering beam line at the ESRF. J. Appl. Crystallogr. 2003, 36, 791-794.

(39) Portale, G.; Cavallo, D.; Alfonso, G. C.; Hermida-Merino, D.; van Drongelen, M.; Balzano, L.; Peters, G. W. M.; Goossens, J. G. P.; Bras, W. Polymer crystallization studies under processing-relevant conditions at the SAXS/WAXS DUBBLE beamline at the ESRF. J. Appl. Crystallogr. 2013, 46, 1681-1689.

(40) Mondeshki, M.; Spiess, H. W.; Aliferis, T.; Iatrou, H.; Hadjichristidis, N.; Floudas, G. Hierarchical self-assembly in diblock copolypeptides of poly(gamma-benzyl-L-glutamate) with poly(Lleucine) and poly(O-benzyl-L-tyrosine). Eur. Polym. J. 2011, 47, $668-674$.

(41) Huang, Y. C.; Yang, Y. S.; Lai, T. Y.; Jan, J. S. Lysine-blocktyrosine block copolypeptides: Self-assembly, cross-linking, and conjugation of targeted ligand for drug encapsulation. Polymer 2012, 53, 913-922.

(42) Politakos, N.; Liontos, G.; Kortaberria, G.; Messman, J. M.; Calvo, J.; Moya, S. E.; Mays, J. W.; Avgeropoulos, A. Comparing Linear and Cyclic Synthetic Homopolypeptides: Synthesis and 
Molecular Characterization. J. Polym. Sci., Part A: Polym. Chem. 2015, 53, 393-404.

(43) Lu, Y. S.; Lin, Y. C.; Kuo, S. W. Separated Coil and Chain Aggregation Behaviors on the Miscibility and Helical Peptide Secondary Structure of Poly(tyrosine) with Poly(4-vinylpyridine). Macromolecules 2012, 45, 6547-6556.

(44) Lu, Y. S.; Kuo, S. W. Miscible polypeptide blends of polytyrosine and poly(gamma-methyl L-glutamate) with rigid-rod conformations. RSC Adv. 2015, 5, 88539-88547.

(45) Castelletto, V.; Newby, G. E.; Hermida-Merino, D.; Hamley, I. W.; Liu, D.; Noirez, L. Self-Assembly of an Amyloid Peptide Fragment/PEG Conjugate: Lyotropic Phase Formation, and Influence of PEG crystallization. Polym. Chem. 2010, 1, 453-459.

(46) Hamley, I. W.; Castelletto, V.; Moulton, C. M.; Myatt, D.; Siligardi, G.; Oliveira, C. L. P.; Pedersen, J. S.; Abutbul, I.; Danino, D. Self-Assembly of a Modified Amyloid Peptide Fragment: $\mathrm{pH}$ Responsiveness and Nematic Phase Formation. Macromol. Biosci. 2010, 10, 40-48.

(47) Hamley, I. W.; Nutt, D. R.; Brown, G. D.; Miravet, J. F.; Escuder, B.; Rodríguez-Llansola, F. Influence of the Solvent on the Self-Assembly of a Modified Amyloid Beta Peptide Fragment. II. NMR and Computer Simulation Investigation. J. Phys. Chem. B 2010, 114, 940-951.

(48) Hamley, I. W.; Dehsorkhi, A.; Castelletto, V.; Seitsonen, J.; Ruokolainen, J.; Iatrou, H. Self-Assembly of a Model Amphiphilic Oligopeptide Incorporating an Arginine Headgroup. Soft Matter 2013, 9, 4794-4801.

(49) Stuart, B. Biological Applications of Infrared Spectroscopy; Wiley: Chichester, U.K., 1997.

(50) Hamley, I. W. Peptide fibrillisation. Angew. Chem., Int. Ed. 2007, 46, 8128-8147.

(51) Dehsorkhi, A.; Castelletto, V.; Hamley, I. W.; Harris, P. J. F. Multiple hydrogen bonds induce formation of nanoparticles with internal microemulsion structure by an amphiphilic copolymer. Soft Matter 2011, 7, 10116-10121.

(52) Hamley, I. W.; Dehsorkhi, A.; Castelletto, V. Self-Assembled Arginine-Coated Peptide Nanosheets in Water. Chem. Commun. 2013, $49,1850-1852$.

(53) Serpell, L. C. Alzheimer's amyloid fibrils: structure and assembly. Biochim. Biophys. Acta, Mol. Basis Dis. 2000, 1502, 16-30.

(54) Takahashi, Y.; Tadokoro, H. Structural studies of polyethers, $\left(-\left(\mathrm{CH}_{2}\right)_{\mathrm{m}}-\mathrm{O}-\right)_{\mathrm{n}} \mathrm{X}$. Crystal structure of poly(ethylene oxide). Macromolecules 1973, 6, 672-675.

(55) Hamley, I. W.; Krysmann, M. J. Effect of PEG Crystallization on the Self-Assembly of PEG/Peptide Copolymers Containing Amyloid Peptide Fragments. Langmuir 2008, 24, 8210-8214.

(56) Krysmann, M. J.; Funari, S. S.; Canetta, E.; Hamley, I. W. The Effect of PEG Crystallization on the Morphology of PEG-peptide Block Copolymers Containing Amyloid $\beta$ Peptide Fragments. Macromol. Chem. Phys. 2008, 209, 883-889.

(57) Castelletto, V.; Newby, G. E.; Zhu, Z.; Hamley, I. W.; Noirez, L. Self-Assembly of PEGylated Peptide Conjugates Containing a Modified Amyloid b Peptide Fragment. Langmuir 2010, 26, 99869996.

(58) Castelletto, V.; Hamley, I. W. Self assembly of a Model Amphiphilic Phenylalanine Peptide/ Polyethylene Glycol Block Copolymer in Aqueous Solution. Biophys. Chem. 2009, 141, 169-174. (59) Tzokova, N.; Fernyhough, C. M.; Butler, M. F.; Armes, S. P.; Ryan, A. J.; Topham, P. D.; Adams, D. J. The Effect of PEO Length on the Self-Assembly of Poly(ethylene oxide)-Tetrapeptide Conjugates Prepared by "Click" Chemistry. Langmuir 2009, 25, 11082-11089.

(60) Mai, S. M.; Fairclough, J. P. A.; Hamley, I. W.; Matsen, M. W.; Denny, R. C.; Liao, B.-X.; Booth, C.; Ryan, A. J. The order-disorder transition in polyoxyethylene-polyoxybutylene diblock copolymers. Macromolecules 1996, 29, 6212-6221.

(61) Mai, S.-M.; Fairclough, J. P. A.; Terrill, N. J.; Turner, S. C.; Hamley, I. W.; Matsen, M. W.; Ryan, A. J.; Booth, C. Microphase separation in poly(oxyethylene)-poly(oxybutylene) diblock copolymers. Macromolecules 1998, 31, 8110-8116.
(62) Beech, D. R.; Booth, C. Unperturbed dimensions of poly(ethylene oxide). Journal of Polymer Science A-2 1969, 7, 575-586.

(63) Hammouda, B.; Ho, D. L. Insight into chain dimensions in PEO/water solutions. J. Polym. Sci., Part B: Polym. Phys. 2007, 45, 2196-2200.

(64) Larson, R. G. The Structure and Rheology of Complex Fluids; Oxford University Press: New York, 1999.

(65) Metzger, T. G. The Rheology Handbook; Vincentz Verlag: Hannover, Germany, 2002.

(66) Mark, J. E. Physical Properties of Polymers Handbook; AIP Press: Woodbury, NY, 1996.

(67) Hamley, I. W. Crystallization in block copolymers. Adv. Polym. Sci. 1999, 148, 113-137.

(68) Hamley, I. W.; Castelletto, V. Small-angle scattering of block copolymers in the melt, solution and crystal states. Prog. Polym. Sci. 2004, 29, 909-948.

(69) Loo, Y.-L.; Register, R. A. Crystallization within block copolymer mesophases. In Developments in Block Copolymer Science and Technology; Hamley, I. W., Ed.; Wiley: Chichester, U.K., 2004; pp 231-243.

(70) Mai, S.-M.; Fairclough, J. P. A.; Viras, K.; Gorry, P. A.; Hamley, I. W.; Ryan, A. J.; Booth, C. Chain folding in semi-crystalline oxyethylene/oxybutylene diblock copolymers. Macromolecules 1997, 30, 8392-8400.

(71) Gottlieb, H. E.; Kotlyar, V.; Nudelman, A. NMR chemical shifts of common laboratory solvents as trace impurities. J. Org. Chem. 1997, 62, 7512-7515.

(72) Bressler, I.; Kohlbrecher, J.; Thünemann, A. F. SASfit: a tool for small-angle scattering data analysis using a library of analytical expressions. J. Appl. Crystallogr. 2015, 48, 1587-1598. 